\title{
Computational Analysis of Natural Ventilation Flows in Geodesic Dome Building in Hot Climates
}

\author{
Zohreh Soleimani ${ }^{1}$, John Kaiser Calautit ${ }^{2, *}$ and Ben Richard Hughes ${ }^{2}$ \\ 1 Department of Architecture and Civil Engineering, University of Bath, Bath BA2 7AY, UK; \\ zohreh_soleimani@yahoo.com \\ 2 Department of Mechanical Engineering, University of Sheffield, Sheffield S10 2TN, UK; \\ ben.hughes@sheffield.ac.uk \\ * Correspondence: j.calautit@sheffield.ac.uk; Tel.: +44-0754-4158981
}

Academic Editor: Demos T. Tsahalis

Received: 2 May 2016; Accepted: 11 August 2016; Published: 17 August 2016

\begin{abstract}
For centuries, dome roofs were used in traditional houses in hot regions such as the Middle East and Mediterranean basin due to its thermal advantages, structural benefits and availability of construction materials. This article presents the computational modelling of the wind- and buoyancy-induced ventilation in a geodesic dome building in a hot climate. The airflow and temperature distributions and ventilation flow rates were predicted using Computational Fluid Dynamics (CFD). The three-dimensional Reynolds-Averaged Navier-Stokes (RANS) equations were solved using the CFD tool ANSYS FLUENT15. The standard k-epsilon was used as turbulence model. The modelling was verified using grid sensitivity and flux balance analysis. In order to validate the modelling method used in the current study, additional simulation of a similar domed-roof building was conducted for comparison. For wind-induced ventilation, the dome building was modelled with upper roof vents. For buoyancy-induced ventilation, the geometry was modelled with roof vents and also with two windows open in the lower level. The results showed that using the upper roof openings as a natural ventilation strategy during winter periods is advantageous and could reduce the indoor temperature and also introduce fresh air. The results also revealed that natural ventilation using roof vents cannot satisfy thermal requirements during hot summer periods and complementary cooling solutions should be considered. The analysis showed that buoyancy-induced ventilation model can still generate air movement inside the building during periods with no or very low wind.
\end{abstract}

Keywords: airflow; buoyancy flow; Computational Fluid Dynamics (CFD); indoor; thermal modelling

\section{Introduction}

The increasing thermal comfort expectations, the availability of electricity generated by fossil fuels and the growth in the global average temperature have raised the energy requirements of mechanical systems (heating, cooling and ventilation) in a rather dramatic way in the building sector, which makes it responsible for $30 \%-40 \%$ of the global energy demand and $40 \%-50 \%$ of the world carbon emissions [1]. Therefore, it is essential to replace the mechanical systems with passive techniques known to have low energy consumption and carbon emissions and provide good indoor air quality $[2,3]$.

Providing an appropriate thermally comfortable environment with acceptable indoor air quality by means of passive techniques could be achieved by coupling passive ventilation with building heat gains reduction. Passive ventilation can be achieved by means of natural ventilation, which relies on pressure differences at the vent openings either by wind-induced force or temperature differences (buoyancy ventilation) [4]. Wind-induced ventilation depends on the behavior of the wind, on the interactions with the envelope of building and on the openings. Fresh outdoor air can be supplied into 
the building from the windward inlets (high pressure) and stale warm indoor air flows out through the leeward outlets (low pressure). Buoyancy-induced ventilation occurs when the indoors are warmer than the outdoors, causing indoor air to rise and escape the building at higher openings. The cooler and denser outdoor air enters the building through bottom inlets and displaces warmer and lighter air upwards [5].

The reduction in energy consumption can be fulfilled by a wide range of factors, including appropriate building geometry, suitable building orientation, use of shading devices, vegetation, colour and insulation [6,7]. In terms of the building geometry, the lower the building surface area to volume ratio, the lower the heat gain would be, so for a given volume, building with a spherical shape is more energy efficient than a typical cubic building in terms of heating and cooling requirements. Accordingly, a dome house has 30\% less surface area than a similarly sized box house, which means one-third less heat transfer to and from its surroundings, resulting in an average of 30\% savings on the cooling and heating bill $[7,8]$.

For centuries, dome roofs were used in traditional houses in the hot, arid regions such as the Middle East and the Mediterranean basin (Figure 1) due to its thermal advantages, structural benefits (self-supporting arch and vault) and availability of the construction materials (adobe, stone).

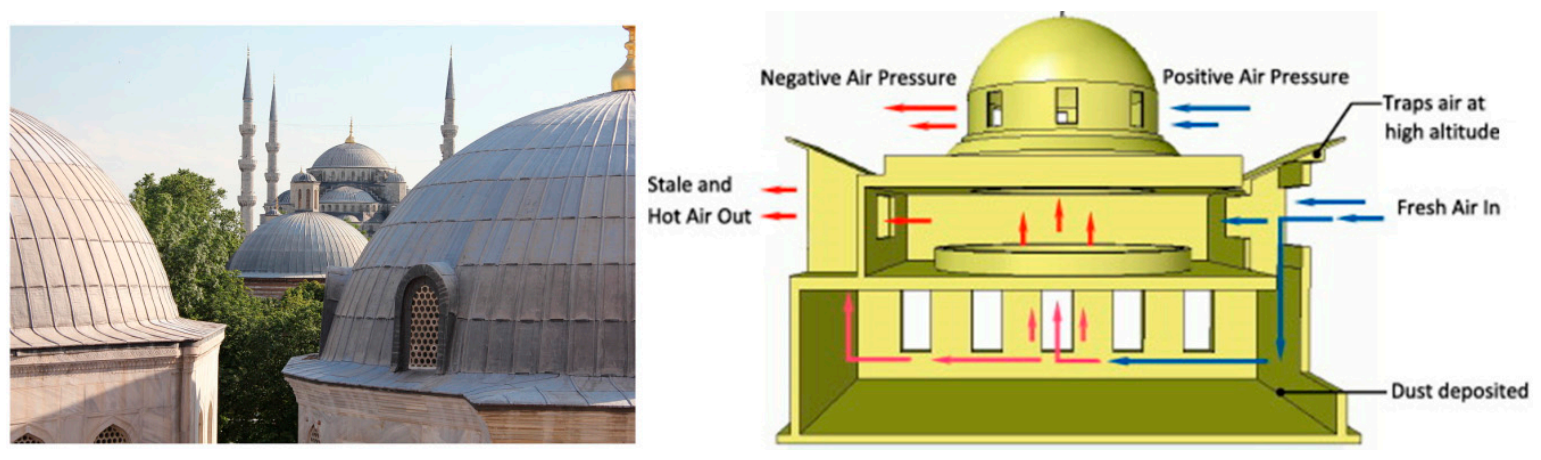

Figure 1. Traditional dome roof building $[9,10]$.

Several studies investigated the passive capabilities of dome roofs in keeping the internal spaces cool in summer with considerable low energy consumption due to several reasons such as:

(a) Thermal lag provision via applying masonry thermal mass such as stone and adobe, which abate the incredible temperature difference between day and night [11].

(b) Lowering exposed surface area to the direct solar radiation by one-third compared to the flat roof results in solar heat gain reduction $[12,13]$.

(c) Applying stack ventilation via roof vents, which let the rising hot air escape through and allow the cool fresh air to channel into the space from small peripheral openings at lower level [14].

(d) Trapping the exhausted, hot air at the higher level compared to the flat roof, due to the increased height of the interior, which leaves the occupants in a cooler lower zone [15].

Currently, the masonry dome roofs are replaced with the geodesic domes which were invented in 1954 by Richard Buckminster Fuller. Figure 2 shows examples of modern geodesic dome buildings. The geodesic dome with partial spherical shape is built up of a series of triangular or polygonal facets that distribute stresses within the structure itself rather than a series of arches, resulting in various shapes and styles with a limitless covering area and a lower weight compared with masonry domes [15]. The geodesic dome has several benefits including an open space plan, non-load bearing interior walls, resistance against excessive wind and seismic vibrations, disaster-proofing, lower construction costs than traditional houses, endless design possibilities and also a spectacular look [15-17]. 

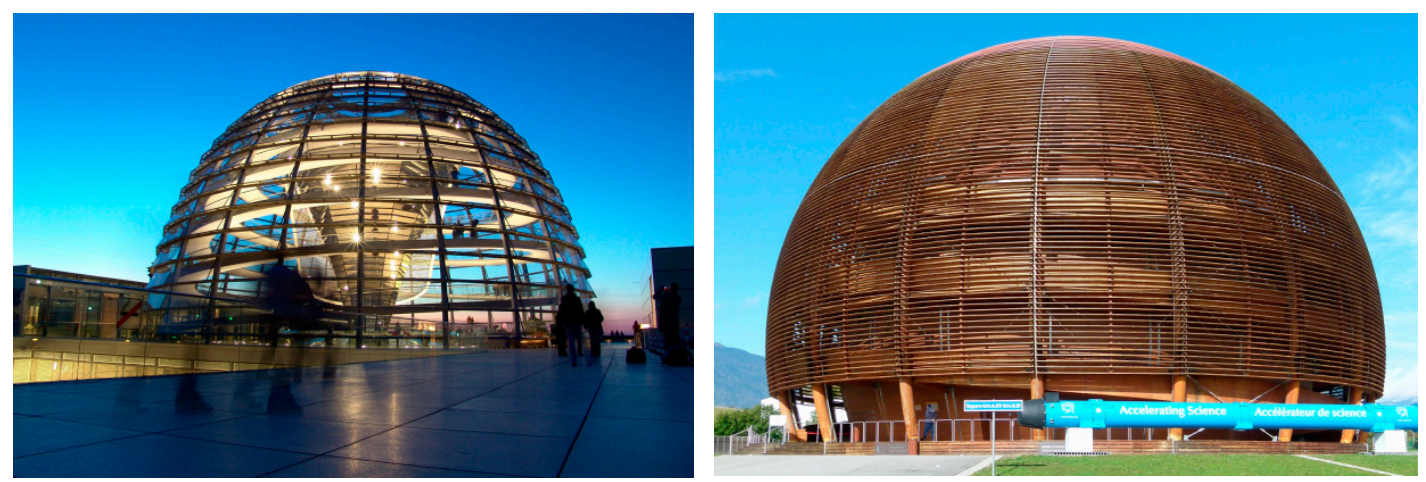

Figure 2. Example of modern geodesic dome building [17,18].

The study evaluates the influence of the geometry of a geodesic dome house as a spherical shape construction on the natural ventilation performance (wind-induced and buoyancy-induced flows) in the hot, arid climatic conditions of Yazd, Iran. Computational Fluid Dynamics (CFD) modelling is conducted to investigate the airflow velocity and indoor temperature distribution within the geodesic dome house. The work will simulate the atmospheric boundary layer (ABL) flow around the geodesic dome, based on vertical wind-speed profiles for the city of Yazd. The boundary conditions will be specified according to guidelines for CFD simulation of wind around buildings as proposed by Architectural Institute of Japan (AIJ). Sensitivity analysis will be carried out to verify the computational model and mesh. In order to validate the numerical code, additional simulation of a similar domed-roof building will be conducted for comparison.

\section{Literature Review}

A few studies have investigated the ventilation performance of dome-shaped roofs or structures. More attention has been given to the airflow pressure over domed roofs and their wind-induced ventilation performance. In this section, a general overview of previous studies, which can be categorized as experimental, analytical and numerical CFD modelling, will be presented including the research aim, methodologies, and the findings.

Faghih and Bahadori [19] evaluated wind pressure coefficient (CP) of a domed roof at different points experimentally. The test was conducted in a wind tunnel with maximum velocity of $70 \mathrm{~m} / \mathrm{s}$ on a 1/10 scale dome model. Twelve openings were considered at the dome collar and one in the apex. The test focused on the dome CP under three different situations. The results showed that the CP reached its maximum at the collar of the dome, with the highest CP of 1 in the first and second cases when the openings and the hole were all opened or closed, and the lowest CP was measured at the apex with -2.3 when the openings and the hole were all closed.

Faghih and Bahadori [20] studied analytically how domed roofs can satisfy thermal requirements during warm seasons considering different parameters such as airflow around domed roofs, solar radiation, radiation heat transfer with the sky and the ground and openings on the property of a theological school in Yazd, Iran. Both ordinary material and glazed tiles were considered for the dome coverage. It was found that the domed roof provided better thermal conditions in summer compared with the flat roof, especially when it was covered with glazed tiles. Moreover, the openings caused passive airflow inside the building, which was useful for meeting thermal comfort.

Atif et al. [21] investigated the optical and thermal performance of a transparent single-glazed hemispherical dome. It was found that at near-normal zenith angels (around the apex) the domed skylight transmitted lower solar radiation and gained lower heat than the planner skylights, whereas the reverse was true for high zenith angles around the horizon. Furthermore, the total daily solar heat gains of the domed skylight were greater than the planner both in summer, with $3 \%$ to $9 \%$, and in winter, up to $232 \%$, by increasing the site latitude. 
Khademinejad et al. [22] explored the floor heating system in a dome-shaped room based on comfort conditions of Tehran, Iran. The author applied CFD modelling to compare the thermal comfort between the room and a rectangular room with the same floor heating system. Key parameters including velocity and internal temperature were evaluated. The results showed that the air temperature and speed were more satisfying in the dome room, where the average of air speed was higher than the cubic room. The total heat transfer from per surface area of the dome room was $23 \%$ less than the cubic room.

Romero-Gómez et al. [23] assessed the internal micro-climate conditions in a naturally ventilated greenhouse under local Mexico climatic conditions. The work applied CFD modelling to examine the effect of different parameters such as roof vent area orientation and insect screen on air exchange rate. The results showed that increasing roof vent area from $6 \%$ to $15 \%$ of the greenhouse floor area enhanced the ventilation rate by $20 \%-40 \%$. Tight insect screens could decrease the airflow rate by almost $50 \%$ of those achieved with normal and without insect screens at the same outside wind speed.

Tlili et al. [24] presented a computational CFD model (VHS approach integrated with a turbulence model) to analyze the effect of the roof shape and the heat source location on the fire-induced airflow pattern. A flat, domed and pyramidal roof were considered for evaluating the temperature, velocity distribution, mass flow rates at the openings and neutral plane height. The results showed that the dome-shaped roof trapped the hot gas in its vicinity resulting in lower temperature inside the room compared with the other two roofs.

Mahdavinejad et al. [25] applied mathematical and CFD analysis to determine the performance of a flat and domed roof in terms of airflow and indoor temperature in Tehran's climatic condition. Results showed that the domed roof caused lower indoor air temperatures of 8 Kelvin compared with the flat roof. Moreover, the geometry of the domed roof caused higher pressure difference between the windward and leeward sides of the house compared with the flat-roofed house resulting in better natural airflow. Furthermore, the heat gain and loss were lower with the domed roof compared with the flat roof.

Lu et al. [26] studied the performance of displacement ventilation in a dome cinema auditorium in summer using CFD modelling. Different arrangements of displacement ventilation were applied to examine internal temperature and air velocity. The supply grills were placed on the floor, whereas three different scenarios were considered for the return grills' location (at the edge of screen, paralleled with the edge, and in a horizontal ring). Results showed that all three scenarios could satisfy the thermal comfort and indoor air quality criteria. Furthermore, farther position of outlets relative to inlets in the horizontal ring scenario provided more upward airflow and better ventilation than the other two scenarios.

Lin et al. [27] presented a three-dimensional thermal and airflow (3D-TAF) model that predicted the impact of large domes on the heating load of a protected house located in Montreal, Canada. The study focused on the airflow model verified with CFD simulations under the COMSOL Multiphysics environment. Based on the investigation, $62.6 \%$ lower annual heating load was reported in the dome house compared with a common insulated house.

Abohela et al. [28] investigated wind flow around six different roof shapes (flat, domed, gabled, pyramidal, vaulted and wedged) covering an insulated cubical building $6 \mathrm{~m}$ high to determine optimum height and roof shape for placing a wind turbine using CFD. The roof shapes' influence was observed in terms of wind-flow patterns, turbulence intensities and streamwise velocities. Based on the investigation, the best location for mounting the wind turbine on top of the domed roof was at 1.3 times the building height, where the maximum streamwise wind velocity was obtained, which was more than the stream-wise velocity at the same location without the building in the flow field.

Several studies have evaluated the ventilation and thermal performance of buildings with dome roofs; however no current work has investigated the geodesic dome type or geodesic dome house. In addition, most studies on dome-type roofs evaluated the internal temperature and air velocity mostly in hot seasons and rarely in cold seasons. Therefore, this study will carry out three-dimensional 
CFD modelling of a two-storey geodesic dome house to investigate its ventilation and thermal performance in different climatic scenarios. The work will look into several ventilation strategies such as wind-driven and buoyancy-driven natural ventilation of the dome-shaped building.

\section{Computational Modelling}

The 3D Reynolds-Averaged Navier-Stokes (RANS) equations along with the momentum and continuity equations were solved using the CFD software FLUENT15. The model employs the control volume technique and the Semi-Implicit Method for Pressure-Linked Equations (SIMPLE) algorithm with the second-order upwind discretisation. The standard k-epsilon (k-e) turbulence model which is frequently used for incompressible flows, was used to define the turbulence kinetic energy and flow dissipation rate within the model [29]. The use of the standard k-e transport model on building configurations has been found accurate in previous works on natural ventilation studies [2-5,30-34]. The governing equations for the mass conservation, momentum conservation, energy conservation, turbulence kinetic energy and dissipation rate are not included here but fully available in the FLUENT user guide [35].

\subsection{Model Geometry}

Geodesic domes are classified into five categories: 1-Icosahedron-based, 2-Octahedron-based, 3-Cube-based, 4-Cuboctahedron-based, 5-Truncated Octahedron-based and 5-Rhombicuboctahedron-based. Icosahedron is the basic form for most geodesic domes, which is categorized into different types named by v suffix, as shown in Figure 3. The $\mathrm{v}$ is the symbol for spatial frequency of a wave in physics and other fields, a measure of how often components of a structure repeat per unit of distance. Therefore, the $\mathrm{v}$ in $2 \mathrm{v}, 3 \mathrm{v}, 4 \mathrm{v}$ geodesic domes stands for their frequency, whereas they can be traced back to the basic form classed as a $1 \mathrm{v}$ geodesic dome. The considered icosahedron dome in this study (see Table 1) was based on a $3 \mathrm{v}$, which has a smoother shape than a $2 \mathrm{v}$ icosahedron dome and lower complexity than a $4 \mathrm{v}$ icosahedron dome [36].

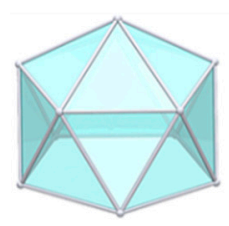

$1 \mathrm{~V}$

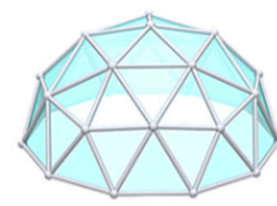

$2 \mathrm{~V}$

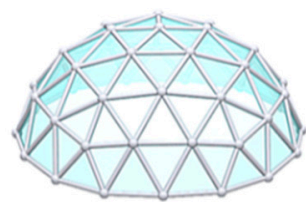

$3 \mathrm{~V} 4 / 9$

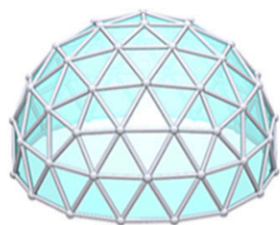

$3 \vee 5 / 9$

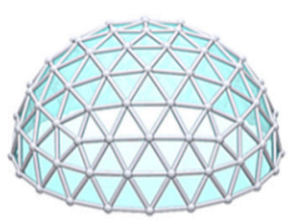

$4 \mathrm{~V}$

Figure 3. Different types of icosahedron-based geodesic domes [36]. Reproduced with permission from Rene K. Mueller, SimplyDifferently.org; published by 2014.

The geometry was generated using a CAD modeller and imported into ANSYS15 for generating the computational domain as shown in Figure $4 \mathrm{~b}$. The computational domain consists of the outdoor domain which represents the environment and the inner domain which represent the geodesic dome house. The outdoor domain consists of an inlet on one corner and pressure outlet on the other side to simulate the wind around the building. The domain size and position of building were based on the guideline for environmental wind-flow studies, COST 732. The guideline suggests that for a building with height of $\mathrm{H}$, the distance between the building's sidewalls and the lateral boundaries of the computational domain should be $5 \mathrm{H}$. For the extension of the domain in flow direction, $5 \mathrm{H}$ was suggested for inlet. For the pressure outlet, the boundary should be positioned at least $15 \mathrm{H}$ behind the building. 

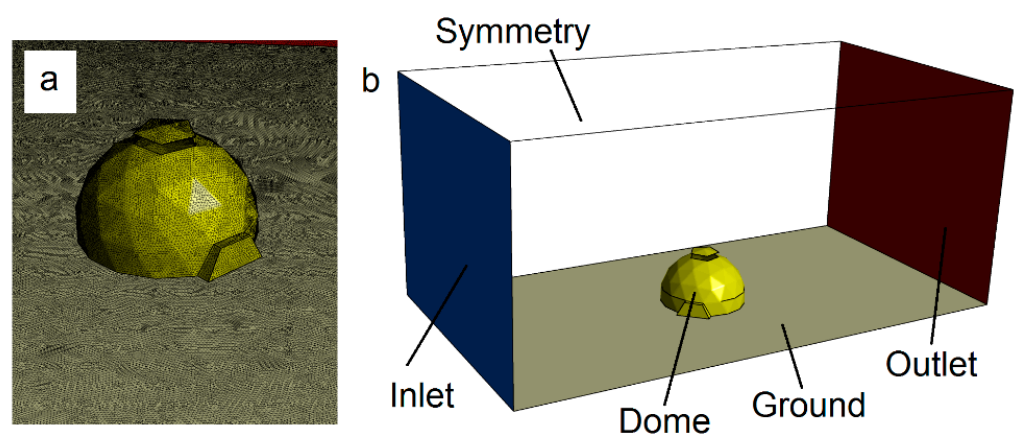

Figure 4. (a) Meshed model (b) Computational flow domain.

Table 1. The specification of the applied 3v 5/9 icosahedron dome in this study.

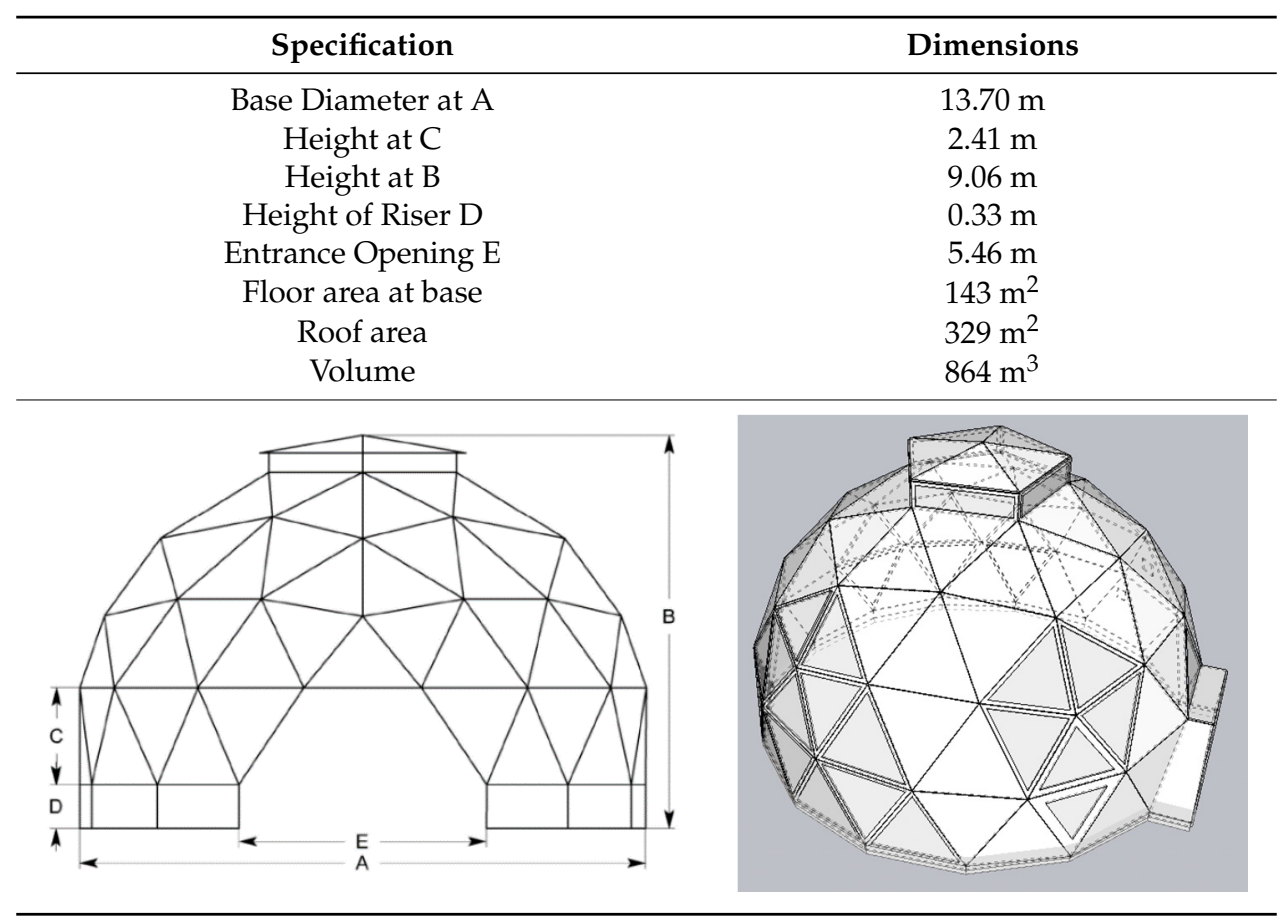

\subsection{Computational Mesh Design}

Due to the complexity of the geometry, the computational model was meshed using unstructured meshing method with patch independent mesh algorithm [29,31-33]. The patch independent mesh algorithm is based on the subsequent spatial subdivision algorithm which ensures refinement of the mesh where essential, but retains larger elements where feasible, therefore allowing faster computing times. Figure $4 \mathrm{a}, \mathrm{b}$ displays the meshed model along with the flow domain used for the CFD analysis. The computational model comprised of 4.6 million elements. The computational modelling was verified using sensitivity analysis and flux balance analysis detailed in the next sections.

\subsection{Sensitivity Analysis}

The computational model used was verified using grid sensitivity analysis which was performed by conducting additional simulations of the same domain and boundary conditions but with various mesh sizes [2-5,31-33]. The area-weighted average value of the velocity measured from a vertical line drawn across the centre of the dome house was used as the error indicator. The vertical line provides analysis of velocity of airflow in different areas and speeds, such as upper areas with high 
speed (>0.8), areas with rotation flows and lower areas with low wind speeds $(<0.2)$. The grid was classified into the following: coarse mesh with 2,910,143 elements, medium with 4,674,895 elements and fine with 8,185,701 elements. Figure 5 shows the summary of the velocity measurements for all the points. The average error between fine and medium mesh results for the velocity was $5.72 \%$, with the maximum error at $9 \%$ (measured at $3.8 \mathrm{~m}$ ) equivalent to $\pm 0.018 \mathrm{~m} / \mathrm{s}$. The average error between fine and medium mesh results for the velocity was 3.79\%, with the maximum error at $9 \%$ (measured at $4.6 \mathrm{~m}$ ) equivalent to $\pm 0.018 \mathrm{~m} / \mathrm{s}$. In order to have a balance between accuracy and computational speed, the medium mesh with 4.6 million elements was employed for all the simulations.

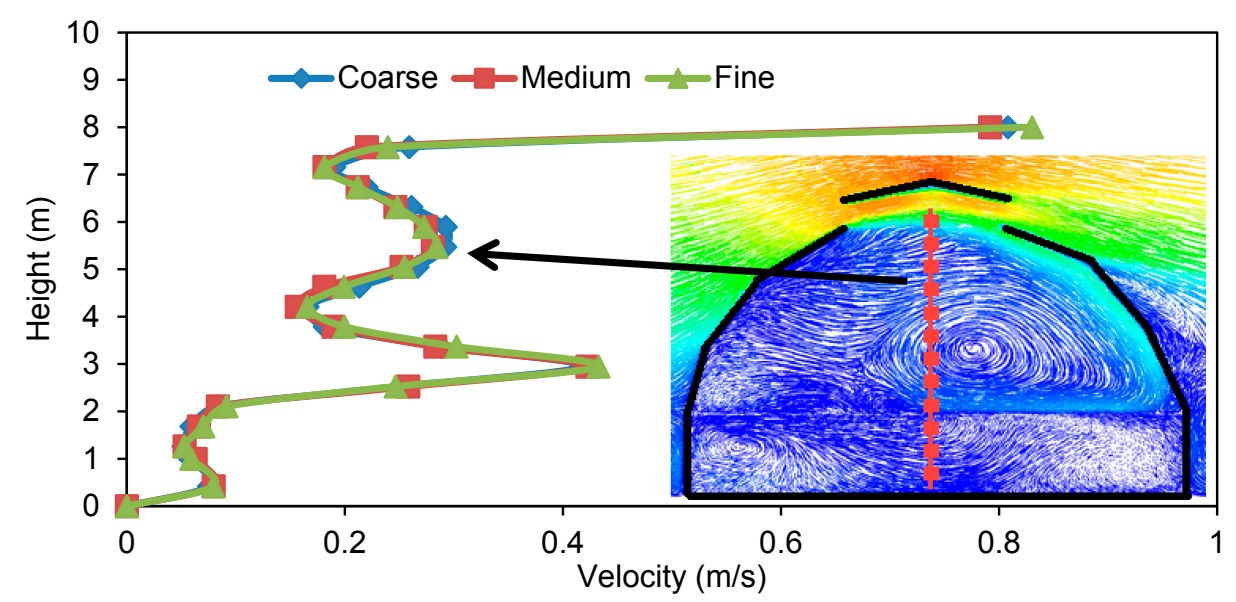

Figure 5. Sensitivity analysis of the computational modelling.

\subsection{Convergence of Solution and Conservation of Property}

Solution convergence is used to approach a zero error in numerical method via applying iterations to produce a solution of the grid. Solutions are based on iterations against pre-defined convergence criterion. FLUENT defined $10^{-6}$ and $10^{-3}$ as the default convergence criterion for the energy equation and all other equations respectively. However, this pre-defined convergence criterion does not apply to all types of simulations and in this study this option was not used and instead the residuals were monitored as shown in Figure 6a. The iteration process is continued until there was no difference between the iterations. In addition, quantities such as the air velocity near the roof ( $9 \mathrm{~m}$ height) and middle (3 m height) (Figure 6b,c) were also monitored. Furthermore, the conservation of properties (mass flux balance) was also achieved. The mass flux balance was below the required value or below $1 \%$ of smallest flux through the computational domain.

\subsection{Method Validation}

In order to validate the modelling method used in the current study, additional simulation of a similar domed-roof building [37] was conducted for comparison. It is worth noting that this particular model was selected because of the similarities with the current work such as the geometry (domed shaped), inlet conditions (ABL type flow), grid (non-uniform with refinement), turbulence model (k-epsilon, standard was used in the current study but RNG in [37]) and modelling procedure (SIMPLE algorithm, finite volume method, etc.). Figure 7 shows a comparison between the numerical results and experimental values of $\mathrm{u}$ (streamwise) and $\mathrm{v}$ (cross-streamwise) components of velocity for location $z / H_{\text {ref }}=-0.163$. It can be seen in Figure 7 that the current model's results have a good agreement with the numerical and experimental data, although the results of the current model were more consistent with the numerical data particularly beyond $y / H_{\text {ref }}=0.2$. In all cases, the $u$ component is lower closer to the ground and increases gradually upwards while the $\mathrm{v}$ component decreases gradually with elevation. Figure 8 displays a comparison between the numerical results and experimental data for streamwise and cross-streamwise velocity flow profiles at $z / H_{\text {ref }}=-0.155$. Similarly, the streamwise 
velocity flow profile was in good agreement with previous works' numerical and experimental results, however, the cross-streamwise velocity flow profile was more consistent with the experimental data for this location. Overall, the numerical code was capable of accurately simulating the wind-flow conditions around a domed-roof building and was therefore employed in this study.
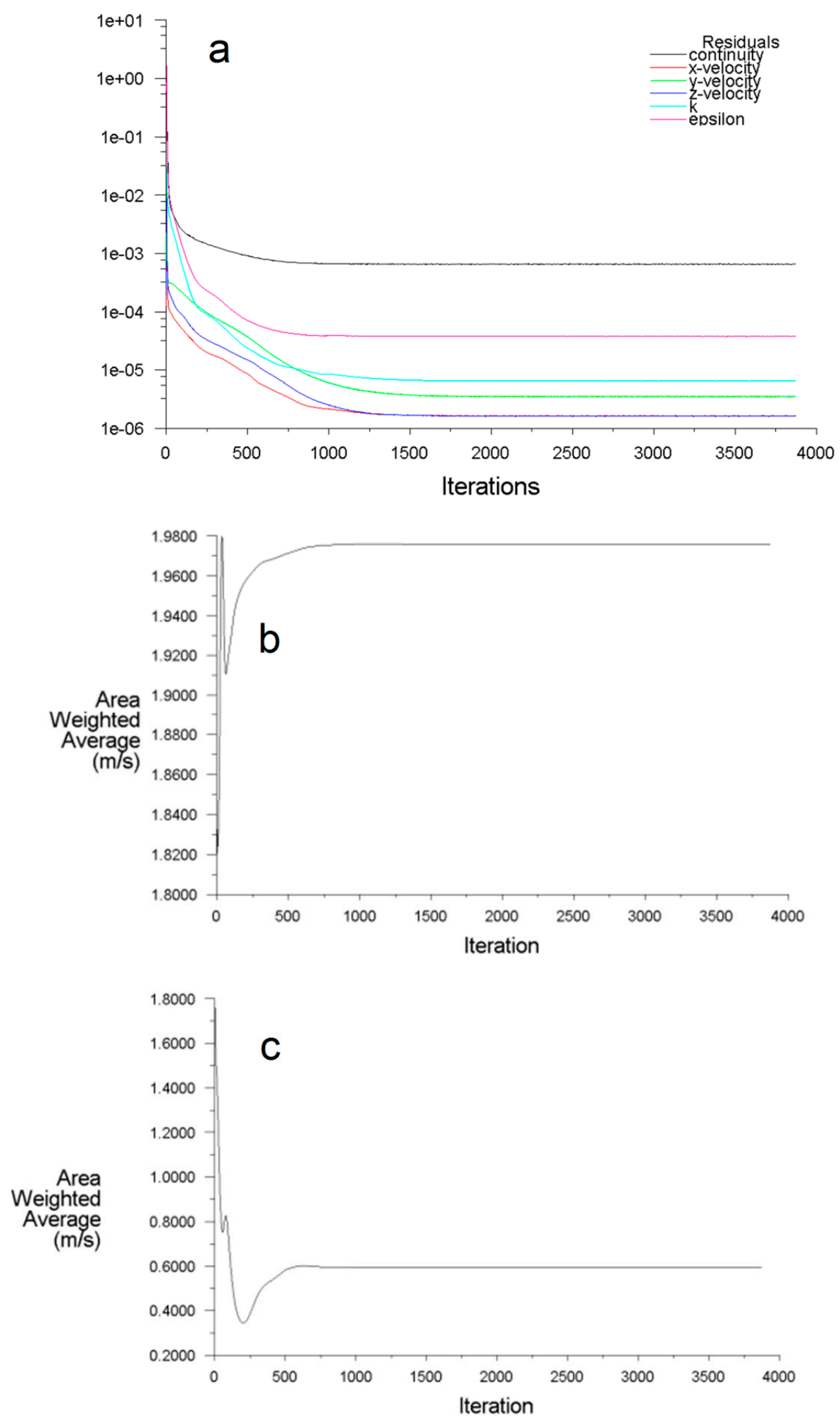

Figure 6. (a) FLUENT solution residuals and monitoring of convergence for (b) velocity at $9 \mathrm{~m}$; and (c) velocity at $3 \mathrm{~m}$. 


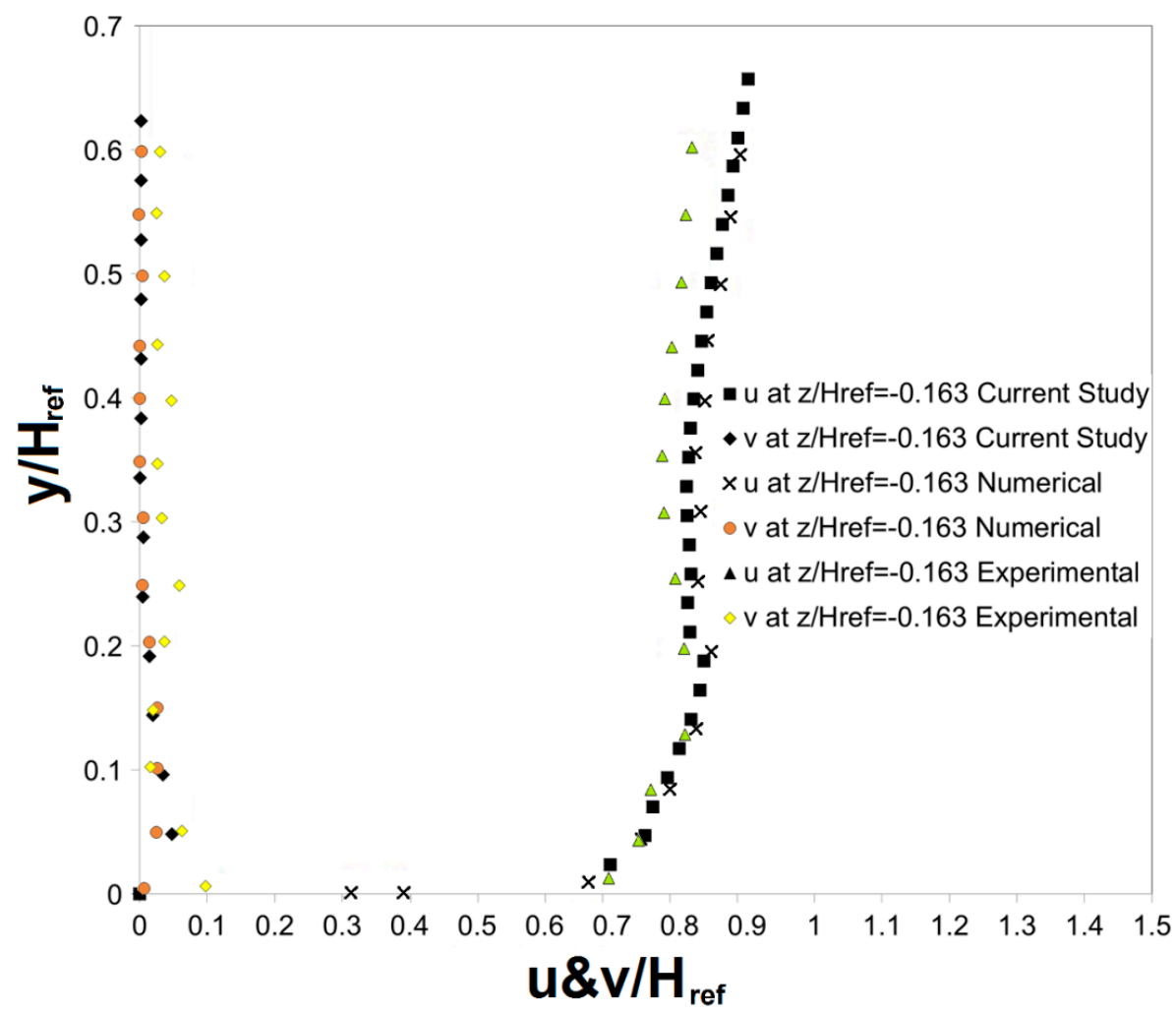

Figure 7. Comparison between numerical predictions and numerical/experimental data [37] for streamwise and cross-stream velocity results at $z / H_{\text {ref }}=-0.163$.

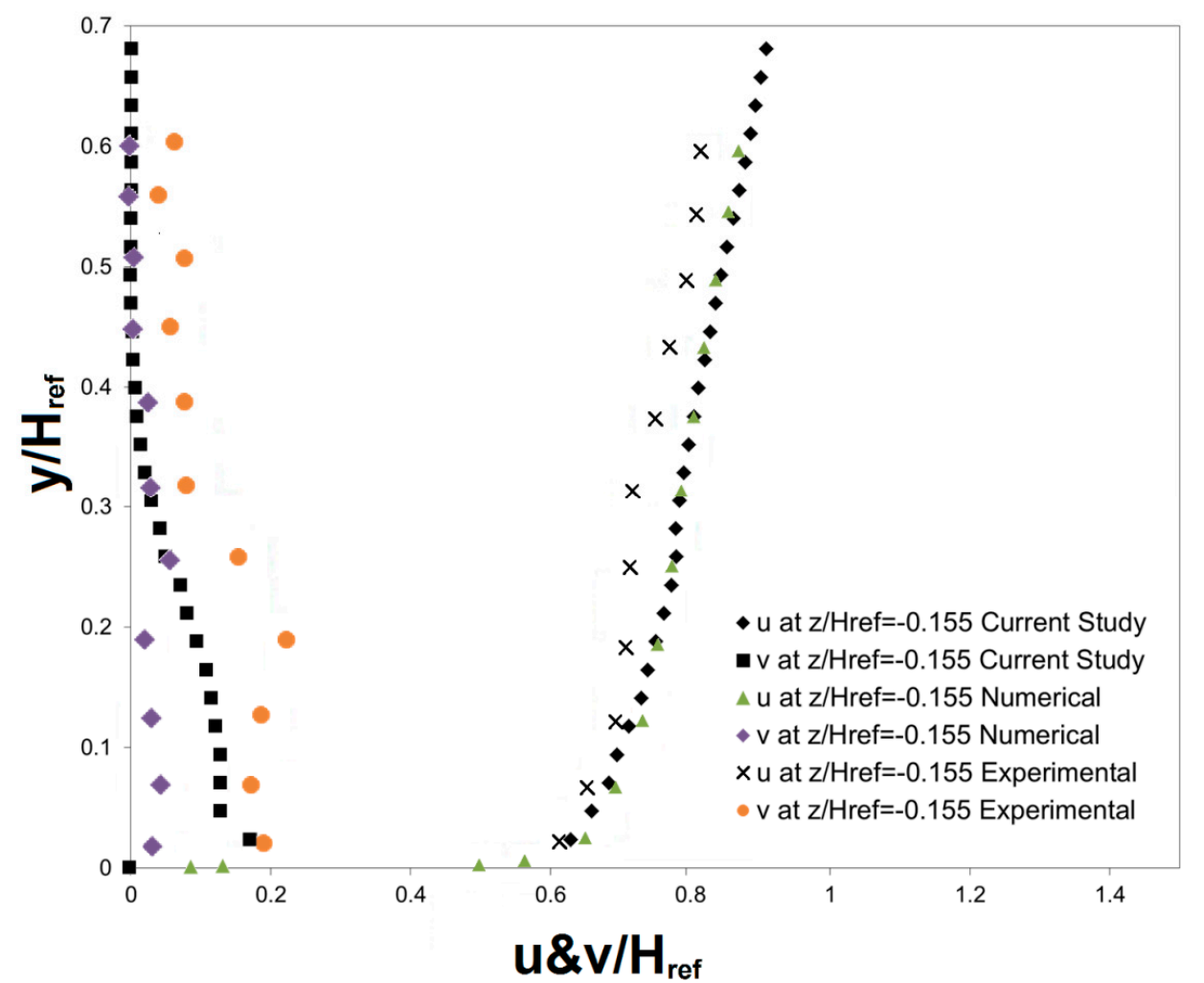

Figure 8. Comparison between numerical predictions and numerical/experimental data [37] for streamwise and cross-stream velocity results at $z / H_{\text {ref }}=-0.155$. 


\subsection{Boundary Conditions}

The basic assumptions for the CFD simulation include a three-dimensional, fully turbulent, and incompressible flow. For the wind-induced flow model, the geometry was modelled as an open structure with openings on the roof which allows the incoming air to pass through it, in order to simulate and analyse the airflow pattern inside the structure. For the buoyancy flow model, the geometry was also modelled as an open structure with openings on the roof and also with windows (one at windward and one at leeward side) open in lower level. The outdoor domain (Figure $4 b$ ) consists of a velocity at the left-hand side, and a pressure outlet (atmospheric pressure) on the opposing boundary wall. The vertical wind-speed monthly profiles in Figure $9 \mathrm{~b}$ were imposed at the inlet of the domain. Mathematical descriptions and derivations of the vertical ABL velocity profile, kinetic energy and dissipation rates are available in [38]. The temperature inlet was also set based on local average temperatures in Figure 9a. The sides and top walls are set as symmetry walls. The standard wall functions were applied to the wall boundaries except for the ground, which had its wall functions adjusted for roughness. In order to simulate indoor heat gains, the heat flux of the floors (upper and lower) of the dome house was set to $25 \mathrm{~W} / \mathrm{m}^{2}$. This was set based on typical internal heat gain levels in residential buildings. This takes into account heat gains from lighting $\left(10 \mathrm{~W} / \mathrm{m}^{2}\right)$, equipment $\left(12 \mathrm{~W} / \mathrm{m}^{2}\right)$ and occupancy $\left(3 \mathrm{~W} / \mathrm{m}^{2}\right)[39,40]$. These values vary greatly based on many factors such as the design, use of space, indoor and outdoor conditions, etc.; however, for the purpose of this study, this was set to a constant value for simplification and should be sufficient for investigating the capabilities of the ventilation strategy to cool the indoor space. The boundary conditions for the CFD model are shown in Table 2.

Table 2. Boundary conditions set for the CFD simulation.

\begin{tabular}{cc}
\hline Parameter & Dimensions \\
\hline Geometry & Solid zone \\
Enclosure & Fluid zone \\
Turbulence Model & Standard k-epsilon \\
Near-Wall Treatment & Standard Wall Functions \\
Velocity Formulation & Absolute \\
Velocity Inlet & ABL Profile (see Section 3.6) \\
Pressure Outlet & Atmospheric \\
Temperature Inlet & see Temperature in Section 3.6 \\
Solver Type & Pressure-Based \\
Time & Steady \\
Gravity & $-9.81 \mathrm{~m} / \mathrm{s}^{2}$ \\
\hline
\end{tabular}

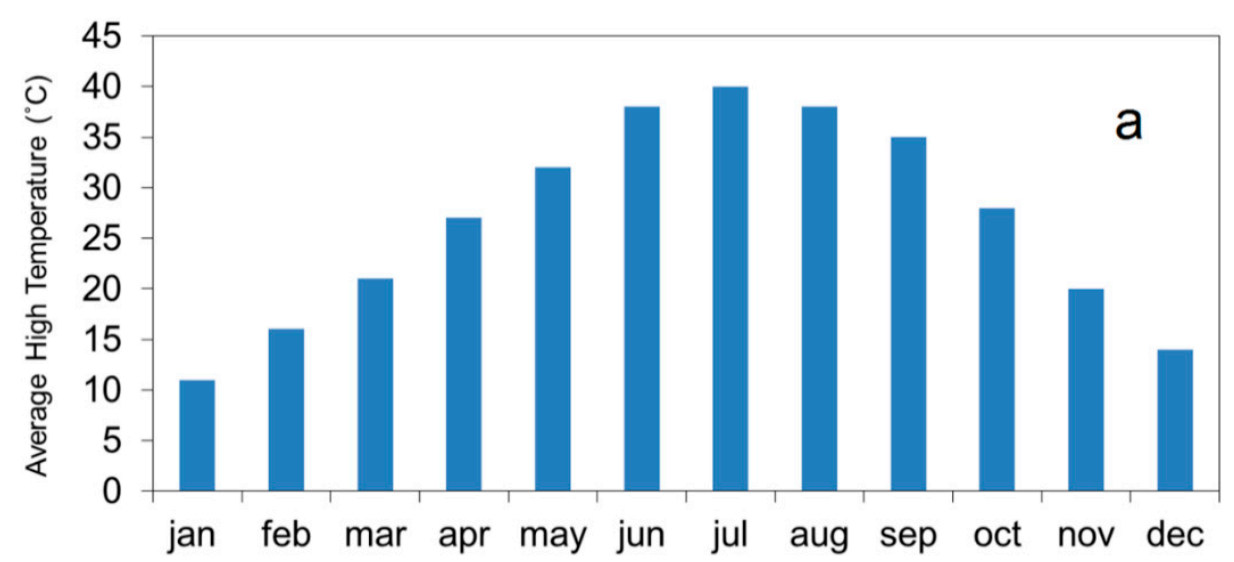

Figure 9. Cont. 


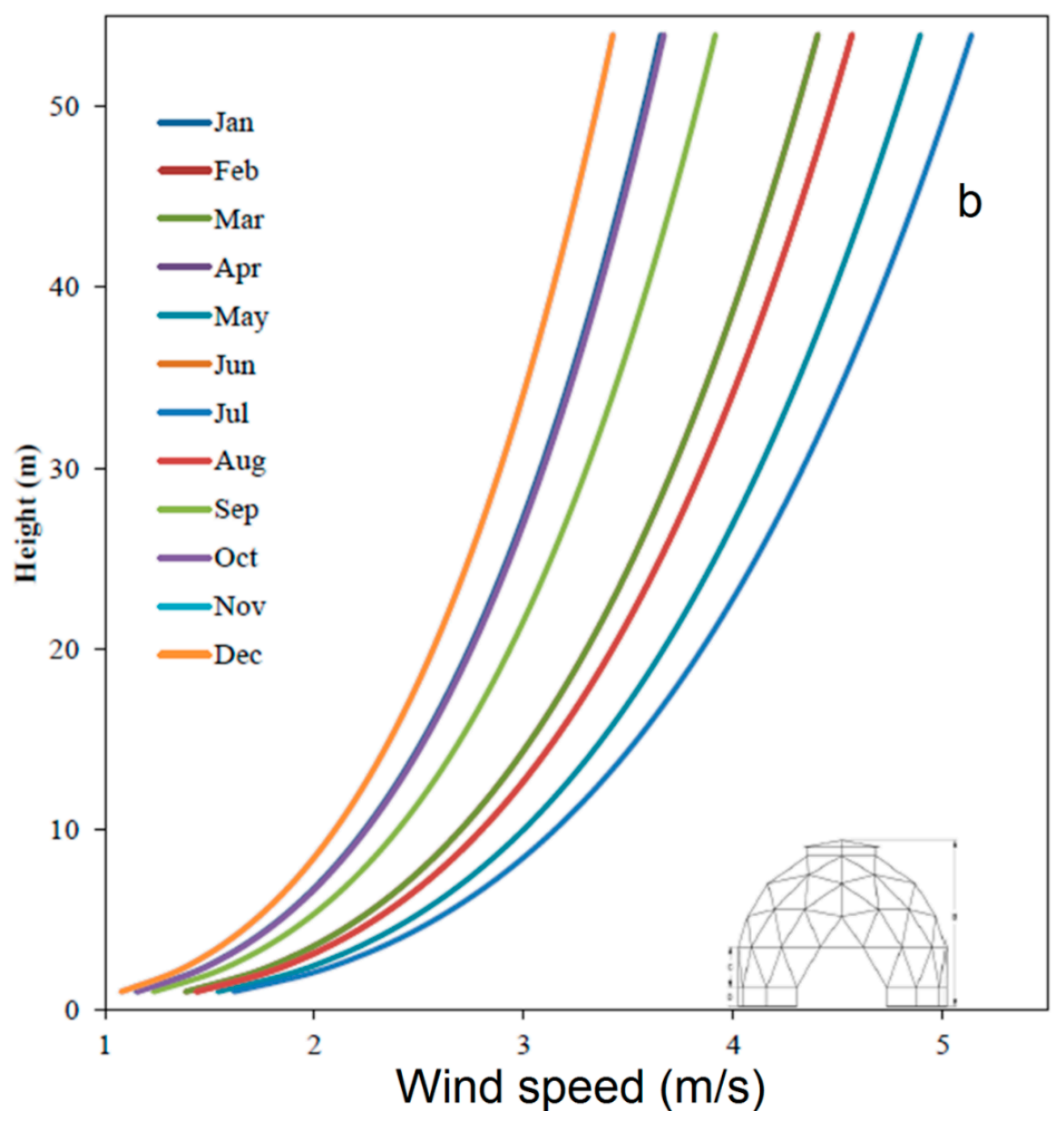

Figure 9. (a) The mean high temperatures [41]; (b) Calculated vertical wind-speed monthly profiles for the city of Yazd [42].

\subsection{Case Study Location}

Yazd is located in the East of Isfahan and south of Lut desert at $31^{\circ} \mathrm{N}$ latitude and $54^{\circ} \mathrm{E}$ longitude. Yazd was used for various months. Monthly temperature and wind-speed profile for different months are shown in Figure 9. Based on Köppen classification, the climatic conditions of this province are categorized as a hot desert climate (BWh). According to the study of [41], Yazd's lower and upper limits of thermal comfort in summer are $294.35 \mathrm{~K}$ and $301.15 \mathrm{~K}$, whereas in winter they are $293.55 \mathrm{~K}$ and $297.95 \mathrm{~K}$ respectively in the centre of Iran. For more realistic prediction of the model, the actual wind profiles [32] for different months were used.

\subsection{Measurement of Indoor Velocity and Temperature}

In order to study wind-flow characteristics, 18 different points (1-9 for lower floor/11-19 for upper floor) at $1.2 \mathrm{~m}$ height and $4.2 \mathrm{~m}$ height were located inside the dome for measuring velocity and temperature (Table 3).

\section{Results and Discussion}

\subsection{Wind-Induced Flows}

During the windy period, ventilation is driven by wind-induced flows. In this case, two side windows were assumed to be closed and the entrance of fresh air and exhaust of stale air were by the top roof vents. 
Table 3. Location of measurement points in lower (1-9) and upper floors (11-19).

\begin{tabular}{|c|c|c|c|c|c|c|c|}
\hline & Points & $X[\mathrm{~m}]$ & $\mathrm{Y}[\mathrm{m}]$ & $\mathrm{Z}[\mathrm{m}]$ & \multirow{6}{*}{$\begin{array}{c}1,11 \\
\oplus\end{array}$} & \multirow{6}{*}{$\begin{array}{c}2,12 \\
\oplus\end{array}$} & \multirow{6}{*}{${ }^{3,13}$} \\
\hline \multirow{9}{*}{ Lower Floor } & 1 & -3.6 & 3.6 & 1.2 & & & \\
\hline & 2 & 0 & 3.6 & 1.2 & & & \\
\hline & 3 & 3.6 & 3.6 & 1.2 & & & \\
\hline & 4 & -3.6 & 0 & 1.2 & & & \\
\hline & 5 & 0 & 0 & 1.2 & & & \\
\hline & 6 & 3.6 & 0 & 1.2 & \multirow{4}{*}{$\stackrel{4,14}{\oplus}$} & \multirow{4}{*}{$\begin{array}{c}5,15 \\
\oplus\end{array}$} & \multirow{4}{*}{$\stackrel{6,16}{\oplus}$} \\
\hline & 7 & -3.6 & -3.6 & 1.2 & & & \\
\hline & 8 & 0 & -3.6 & 1.2 & & & \\
\hline & 9 & 3.6 & -3.6 & 1.2 & & & \\
\hline \multirow{9}{*}{ Upper Floor } & 11 & -3.6 & 3.6 & 4.2 & \multirow{9}{*}{$\stackrel{7,17}{\oplus}$} & \multirow{9}{*}{$\begin{array}{r}8,18 \\
\oplus\end{array}$} & \multirow{9}{*}{$\begin{array}{c}9,19 \\
\oplus\end{array}$} \\
\hline & 12 & 0 & 3.6 & 4.2 & & & \\
\hline & 13 & 3.6 & 3.6 & 4.2 & & & \\
\hline & 14 & -3.6 & 0 & 4.2 & & & \\
\hline & 15 & 0 & 0 & 4.2 & & & \\
\hline & 16 & 3.6 & 0 & 4.2 & & & \\
\hline & 17 & -3.6 & -3.6 & 4.2 & & & \\
\hline & 18 & 0 & -3.6 & 4.2 & & & \\
\hline & 19 & 3.6 & -3.6 & 4.2 & & & \\
\hline
\end{tabular}

\subsubsection{Velocity Distribution (Wind-Induced Flows)}

Figure 10a shows the airflow velocity streamlines inside the dome house with the top vents open to ventilate the space. In this case, the windows were assumed to be fully closed. As observed, the wind enters from the left velocity-inlet wall and lower airflow speed can be observed towards the ground of the domain (atmospheric boundary layer flow). The airflow can be seen lifting up as it approaches the dome house and accelerates near the top where the vents are located. The top vents capture some of the airflow and recirculates it mainly in the upper floor area. The air that passed through the dome can be seen recirculating at the back side and then exits towards the right side of the domain where the pressure-outlet is located. The recirculating airflow pattern at the upper floor is positioned in the windward region of the building, which indicates a mainly positive vertical airflow in the most windward portion of the building and a negative vertical direction in the middle and leeward portion of the building.

Figure $10 \mathrm{~b}$ shows the velocity contours plotted along the vertical central plan passing through the building to illustrate airflow distribution in and around the geodesic dome. The left-hand side of the plot shows the scale of airflow velocity $(\mathrm{m} / \mathrm{s})$. The contour plot in the fluid domain is colour coded and related to the CFD colour map, ranging from 0 to $4.4 \mathrm{~m} / \mathrm{s}$ and 0 to $3.2 \mathrm{~m} / \mathrm{s}$ for summer and winter cases respectively. For the summer case, the plot displayed that the air velocity gradually decreased to $1.5 \mathrm{~m} / \mathrm{s}$ from a reference velocity of $3.15 \mathrm{~m} / \mathrm{s}$ after entering the geodesic dome. On average, the air velocity was $24 \%$ higher at the upper level in relation to the lower level during summer. Figure 11 shows the airflow velocity at different points inside the geodesic dome during different months. In addition, maximum velocity was achieved in the upper floors of the geodesic (points 18-19-16) with a maximum value of $0.22 \mathrm{~m} / \mathrm{s}$. In contrast, the lowest velocity was measured at the center of the lower floor; point 5 with $0.05 \mathrm{~m} / \mathrm{s}$. As with the summer case, in winter the average velocity was higher at the upper floor compared with the lower floor by 33\%. During winter, points 18 and 5 showed respectively the maximum and minimum velocity value with $0.17 \mathrm{~m} / \mathrm{s}$ and $0.05 \mathrm{~m} / \mathrm{s}$. 


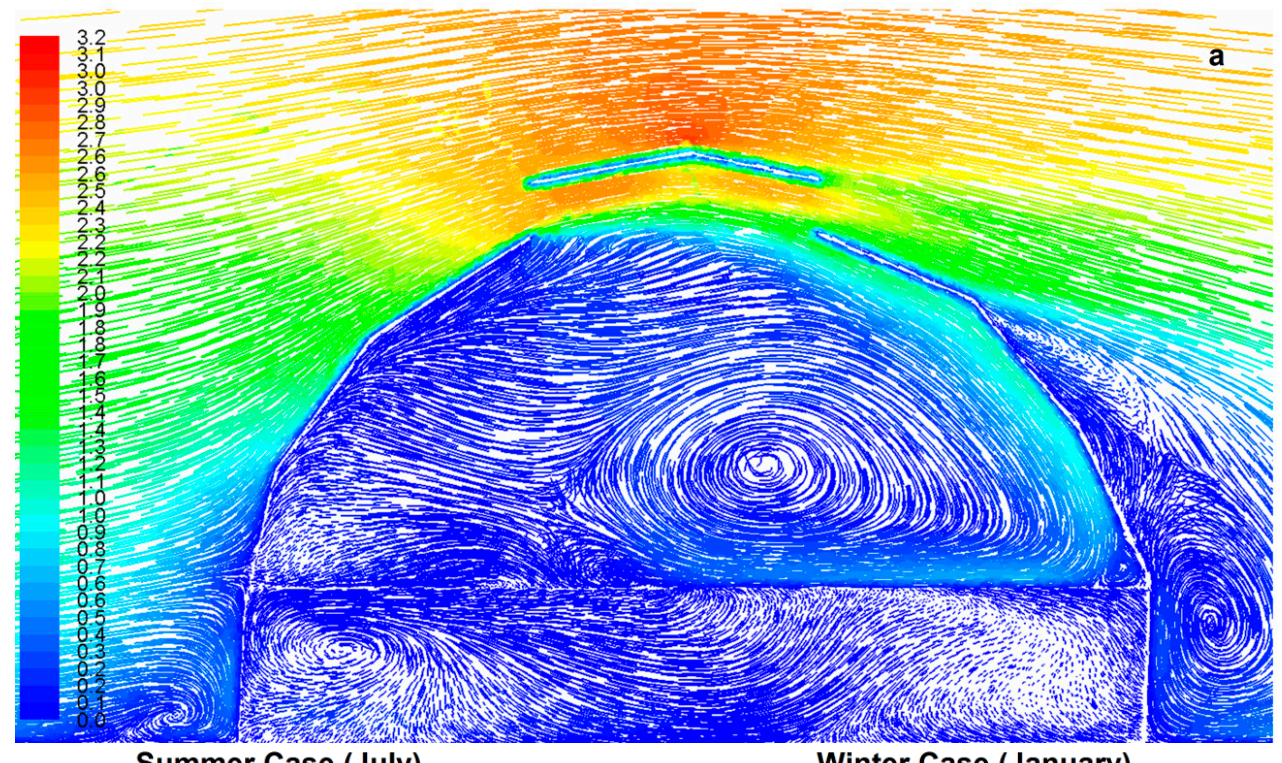
Summer Case (July)

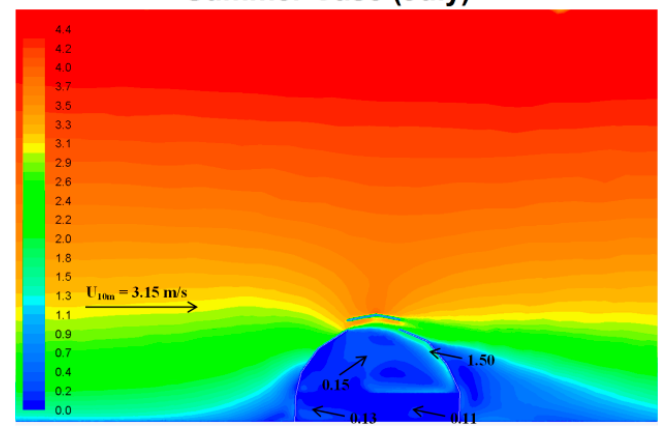

Winter Case (January)

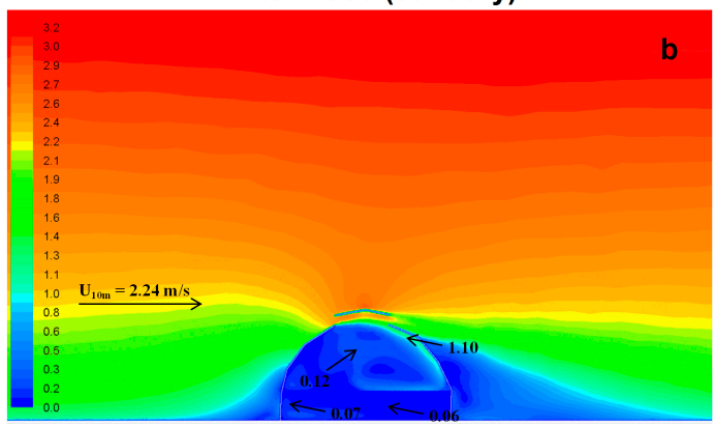

Figure 10. (a) Streamline plot of velocity inside the dome during summer with wind-induced flow; (b) Velocity contour results of the airflow distribution inside the dome (wind-induced flows).

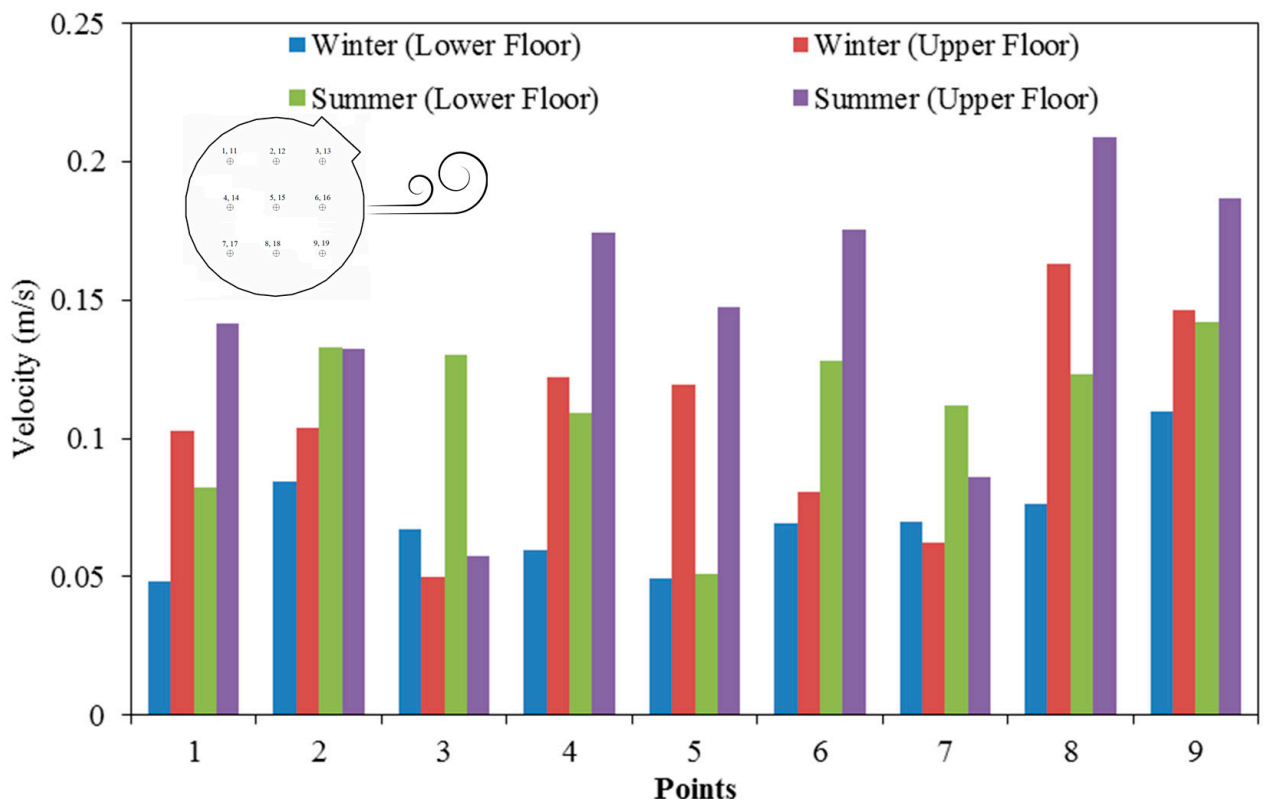

Figure 11. Comparison of the airflow velocity distribution inside the dome house during winter and summer (wind-induced flows). 


\subsubsection{Temperature Distribution (Wind-Induced Flows)}

Figures 12 and 13 illustrate cross-sectional plots of the temperature distribution inside the domed room in the month of July and January. The left-hand side of the contour shows the scale of static temperature $(\mathrm{K})$. The contour plot in the fluid domain is colour coded and related to the CFD colour map, ranging from $284 \mathrm{~K}$ to $320 \mathrm{~K}$. For the summer case, it can be observed that the upper floor (315-317.5 K) was at a lower temperature as compared to the lower floor (318-320 K) which is due to the higher airflow in the upper floor coming from the outdoor $(313 \mathrm{~K})$ via the roof openings. Clearly, in order to achieve comfortable temperature levels inside the dome during this period, a mechanical system or integration of other cooling strategies (evaporative cooling, etc.) is necessary. A similar pattern can be observed for the winter case (Figure 13), with the upper floor at a lower temperature as compared to the lower floor. Using the upper roof vents as a natural ventilation strategy during winter periods is advantageous and could reduce the indoor temperature and also introduce fresh air. A flow control system can be integrated with the roof vents to optimise the indoor velocity and temperature.

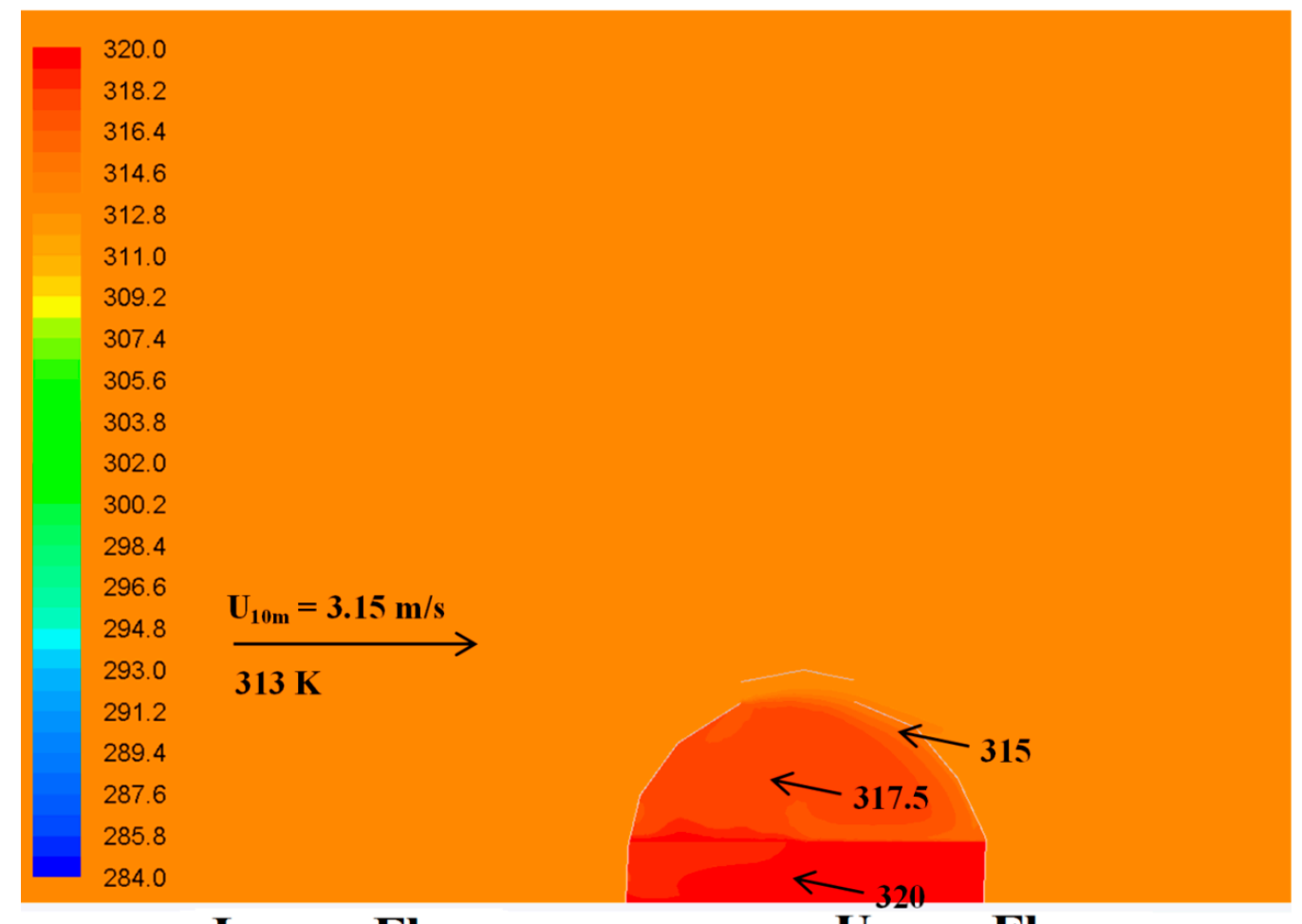

Lower Floor

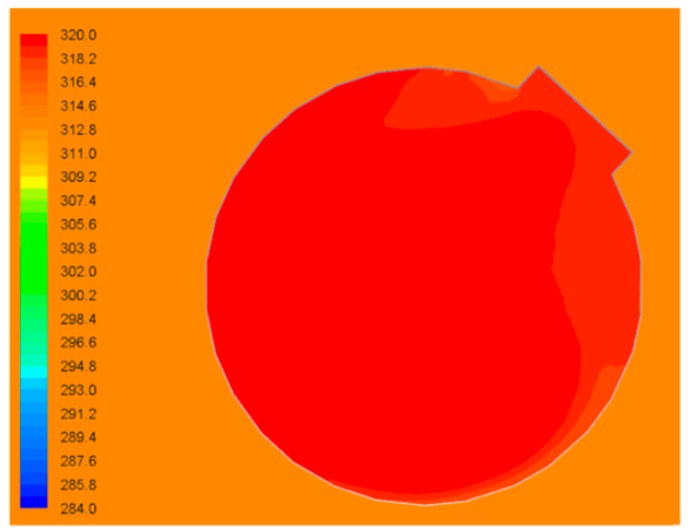

Upper Floor

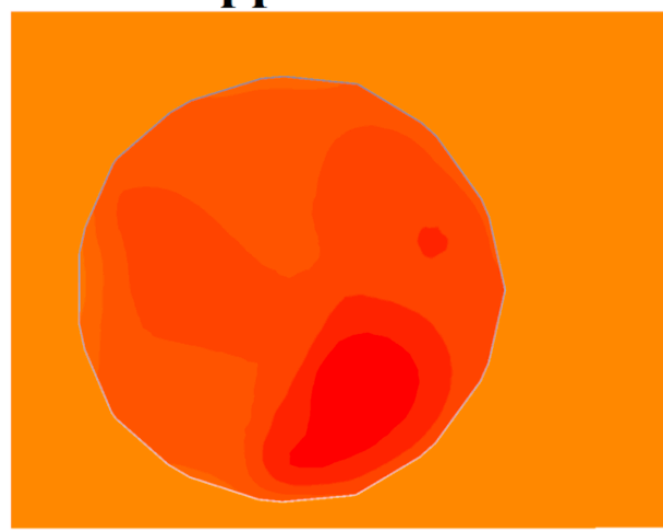

Figure 12. Mid-plane contour plot of the temperature distribution inside the dome during summer month of July (wind-induced flows). 

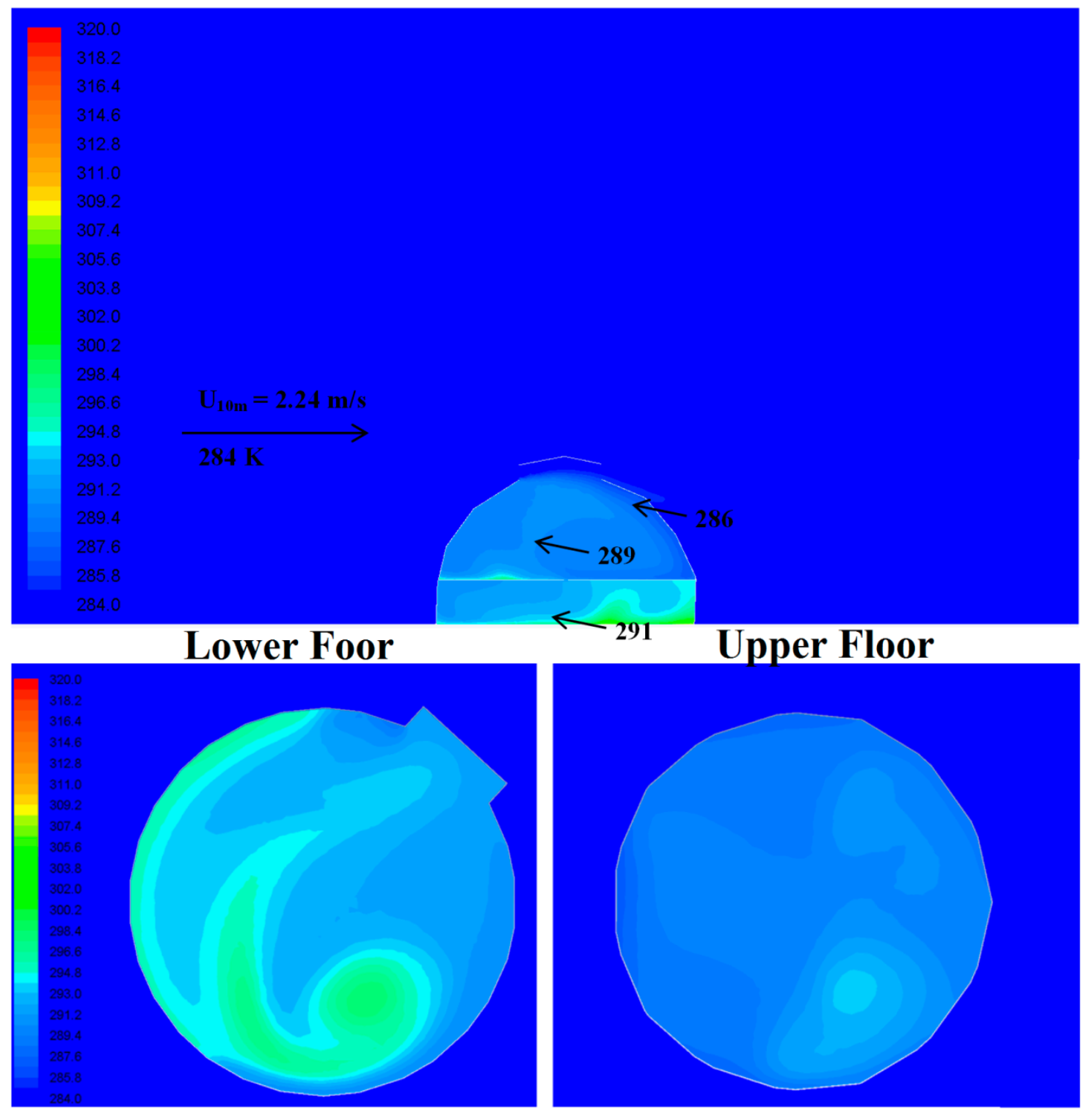

Figure 13. Comparison of the airflow velocity distribution inside the dome house during winter month of January (wind-induced flows).

Figure 14 shows the temperature distribution inside the dome in upper and lower floors during summer and winter scenarios. In summer, the average internal temperature was recorded at $317.5 \mathrm{~K}$ for the upper floor and $320 \mathrm{~K}$ for the lower, when the external temperature was set at $313 \mathrm{~K}$. Furthermore, the minimum temperature was $315 \mathrm{~K}$ as recorded at the entrance of the airflow into the dome zone, and the maximum value was $320 \mathrm{~K}$, as measured on the lower floor, thereby indicating the warmer conditions of the lower floor compared with the upper floor. For the winter case, the external temperature was set at $284 \mathrm{~K}$. The average internal temperature was $290 \mathrm{~K}$ for the upper floor and $293 \mathrm{~K}$ for the lower floor, whereas $295 \mathrm{~K}$ (points 7-9) and $289 \mathrm{~K}$ (points 11, 12, 17) were the maximum and minimum recorded values. 


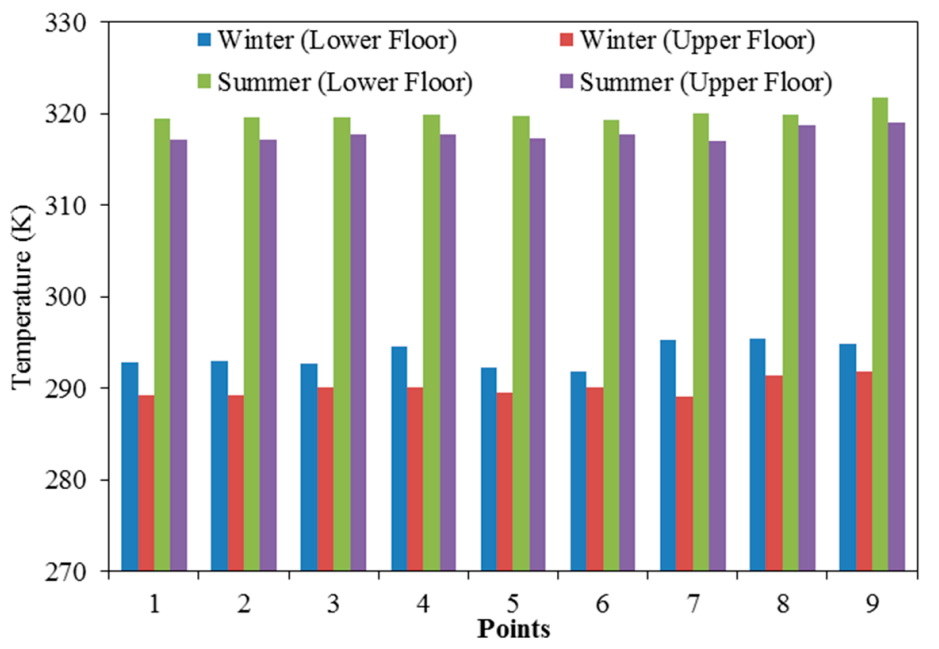

Figure 14. Comparison of the airflow temperature distribution inside the dome house during winter and summer (wind-induced flows).

\subsection{Buoyancy-Induced Flows}

During periods of very low to no wind, fresh outdoor air can still be induced inside the building using the buoyancy forces from heated air which creates flow from the lower floor to the upper floor as shown in Figure 15. In this case, two side windows were assumed to be open to allow fresh air to enter from outside and replace the warm and stale air inside the dome house. The stale air is then exhausted by the top roof vents.

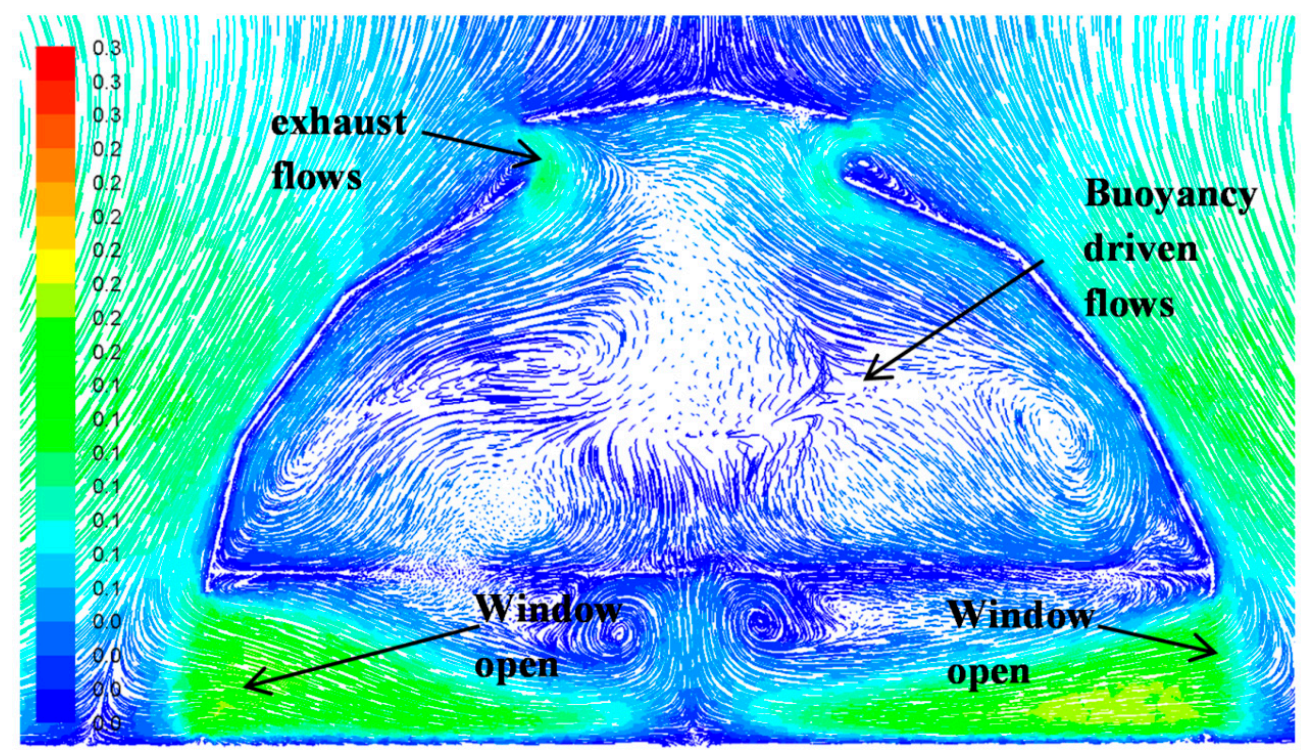

Figure 15. Streamline plot of velocity inside the dome during winter with very low or no wind speed.

\subsubsection{Velocity Distribution (Buoyancy-Induced Flows)}

Figure 15 shows the airflow velocity streamlines inside the dome house with the two side windows and top roof vents open. Clearly, the air velocity distribution in the buoyancy case is more non-uniform compared with the wind-driven case. The cooler ambient air flowed into the building from the two side windows and then flowed along the floor where it picked up heat. The heated air moved upwards to the upper floor due to buoyancy and makes a large separation zone at the center of the upper floor. Shearing with the dome walls at the upper floor, the air moved upward toward the roof vents where 
its velocity accelerated before leaving the building. It can be seen that the air movement in the lower floor near to the windows (points 6 and 4) was larger than that in the upper floor and the lowest air velocity values were observed away from openings. In addition, the velocity values were larger near the windows than the roof vent openings.

Figure 16 shows the velocity distribution inside the building during typical summer and winter conditions. For the summer season, the maximum velocity values were $0.21 \mathrm{~m} / \mathrm{s}$ and $0.11 \mathrm{~m} / \mathrm{s}$ respectively at points 6 and 4 which were close to the side windows. In contrast, the lowest velocity was measured at the upper floor, point 18 with $0.027 \mathrm{~m} / \mathrm{s}$. During winter, points 6 and 4 showed the highest values with $0.35 \mathrm{~m} / \mathrm{s}$ and $0.077 \mathrm{~m} / \mathrm{s}$, and point 16 had the lowest value with $0.004 \mathrm{~m} / \mathrm{s}$.

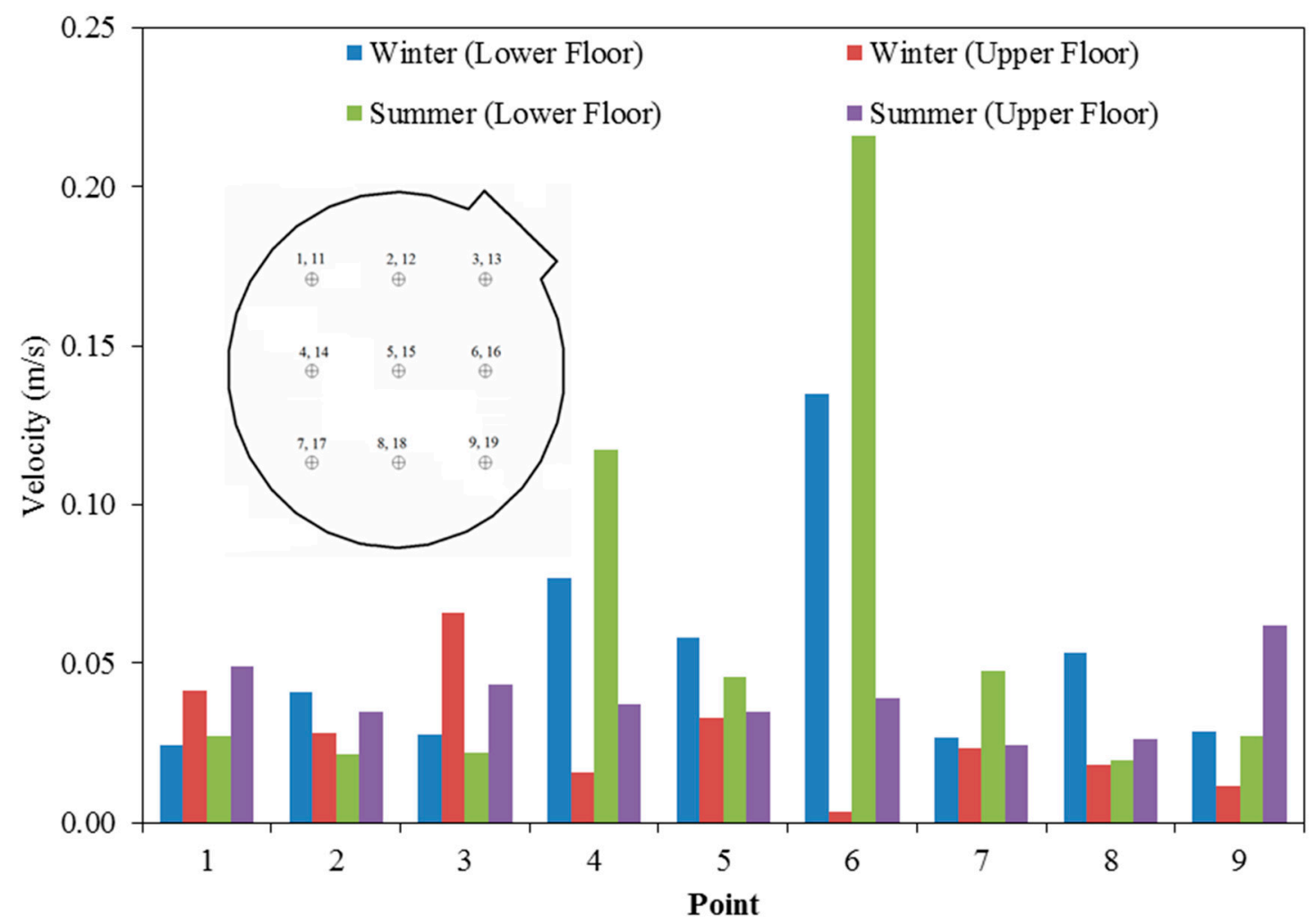

Figure 16. Comparison of the airflow speed distribution inside the dome house during winter and summer (buoyancy-induced flows).

\subsubsection{Temperature Distribution (Buoyancy-Induced Flows)}

Figures 17 and 18 illustrate cross-sectional plots of the temperature distribution inside the domed room in the month of July and January. Accordingly, airflow temperature is lower in the lower zone near to the two side inlets, which increases away from the opening at the center and the upper floor. Furthermore, due to the geometry of the building, hot, stale air has an upward current toward the roof vents by moving along the dome walls. As a result, the center of the upper floor is cooler than its corners. During winter, the ventilation strategy can effectively lower the temperature inside the building particularly in the lower floor. A flow control system can be integrated with the openings to optimise the indoor velocity and temperature during the winter period. Similar temperature distribution can be observed during the summer with the outdoor air entering from the lower openings and stale air rising towards the exhaust stack. However, due to the already high outdoor temperatures during summer, the resulting indoor temperature would cause discomfort to occupants and mechanical or evaporative cooling is necessary during this period.

In the summer, the average internal temperature was recorded at $320 \mathrm{~K}$ for the upper floor and $317 \mathrm{~K}$ for the lower, when the external temperature was set at $313 \mathrm{~K}$. Further, the minimum 
temperature was $315 \mathrm{~K}$ near the side windows, at the entrance of the airflow into the building, and the maximum value was 320 as measured at the upper floor near the dome perimeter, indicating the warmer conditions of the upper floor compared with the lower floor as Figure 19 shows. For the winter case, the external temperature was set at $284 \mathrm{~K}$. The average internal temperature was recorded at $292 \mathrm{~K}$ for the upper floor and $289 \mathrm{~K}$ for the lower floor, whereas $297 \mathrm{~K}$ (points 4-6) and $294 \mathrm{~K}$ (points 18 and 19) were the maximum and minimum recorded values respectively.

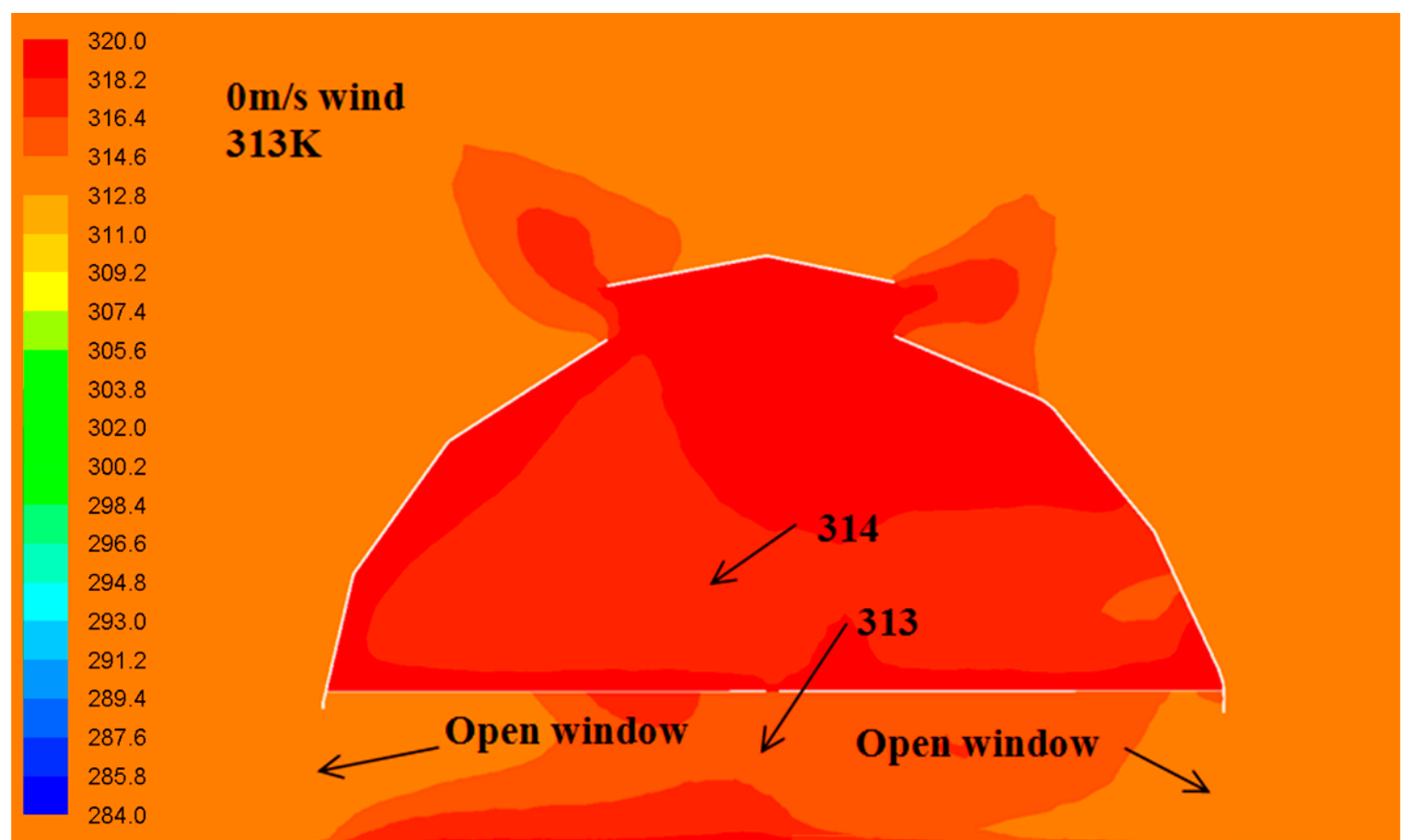

\section{Lower Floor}

Upper Floor

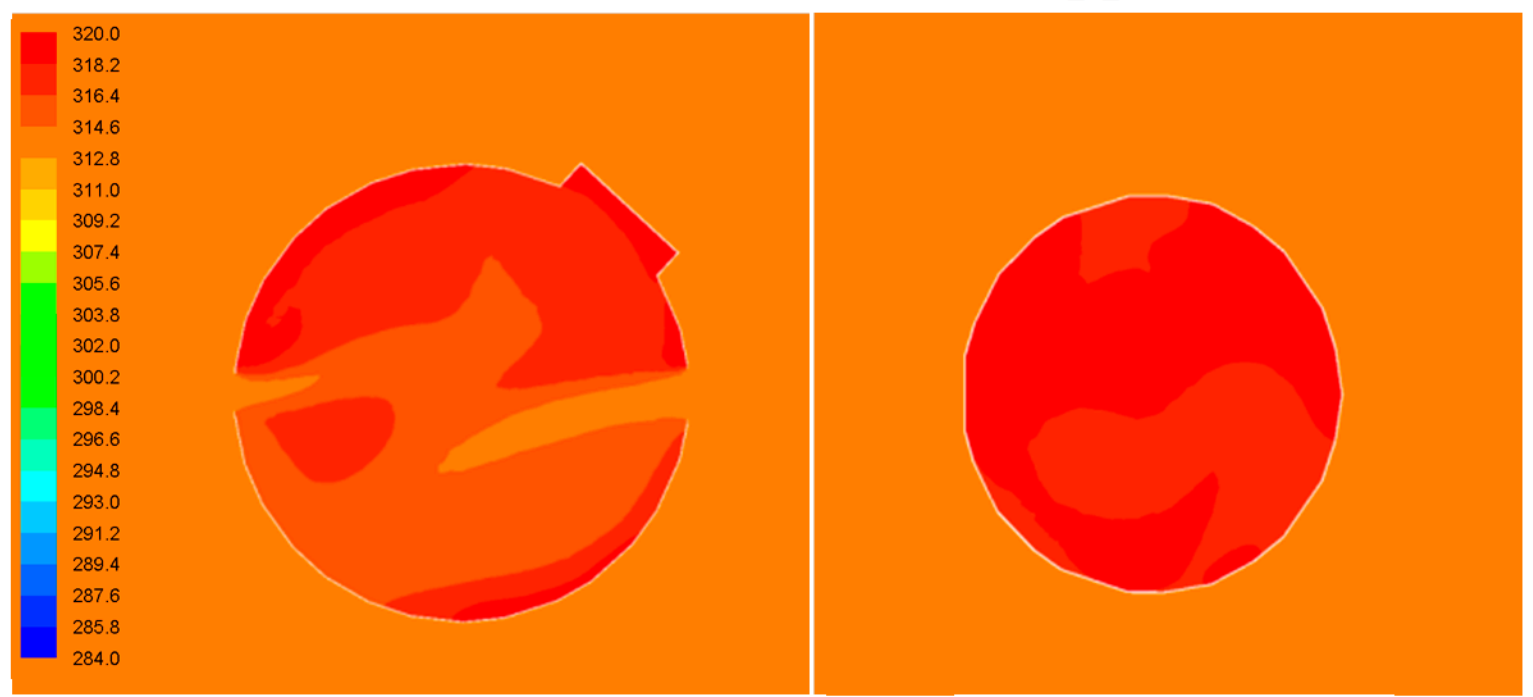

Figure 17. Comparison of the airflow speed distribution inside the dome house during winter and summer (buoyancy-induced flows). 


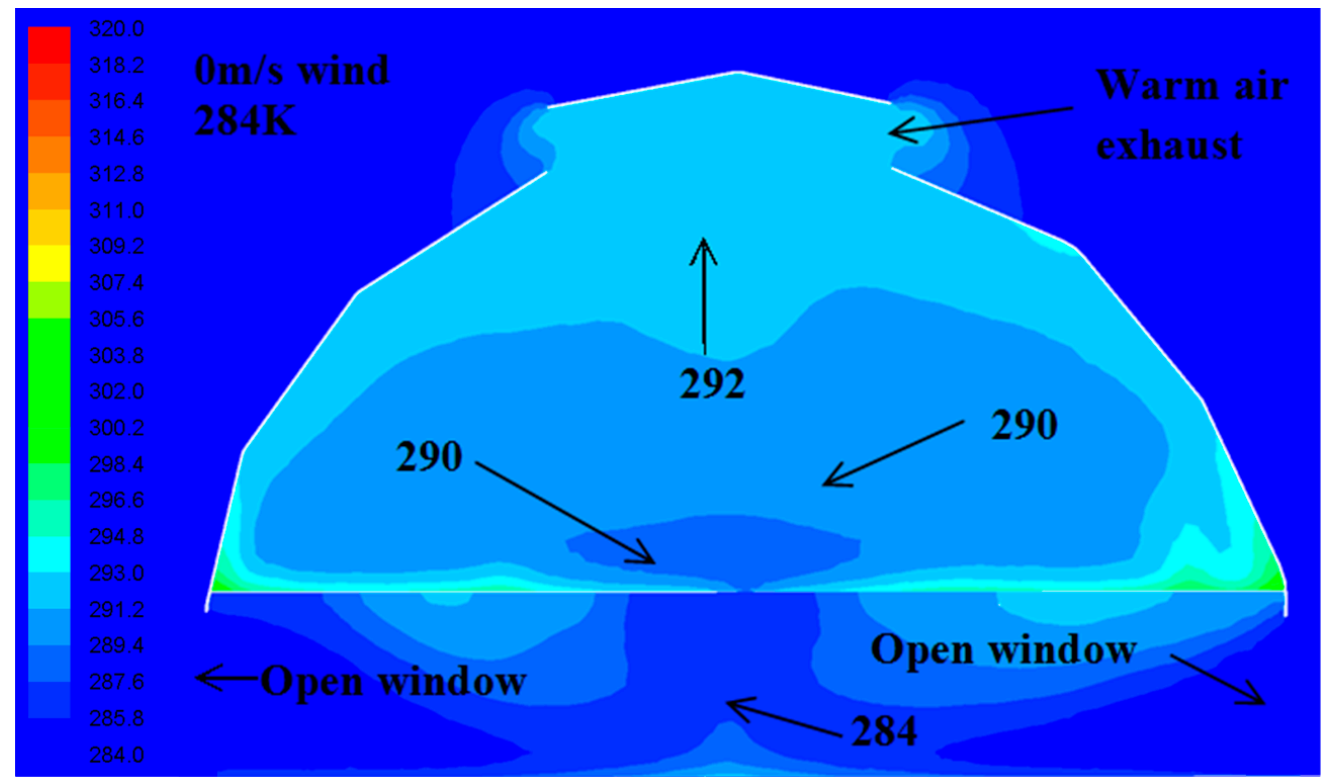

Lower Floor

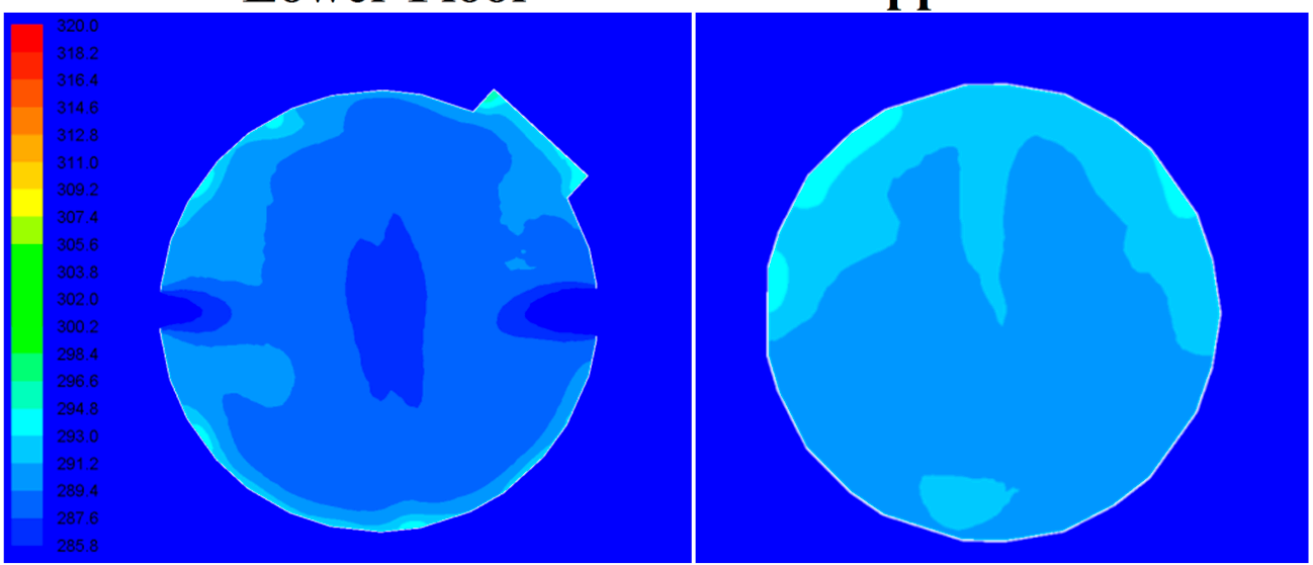

Figure 18. Mid-plane contour plot of the temperature distribution inside the dome with during summer and winter (buoyancy-induced flows).

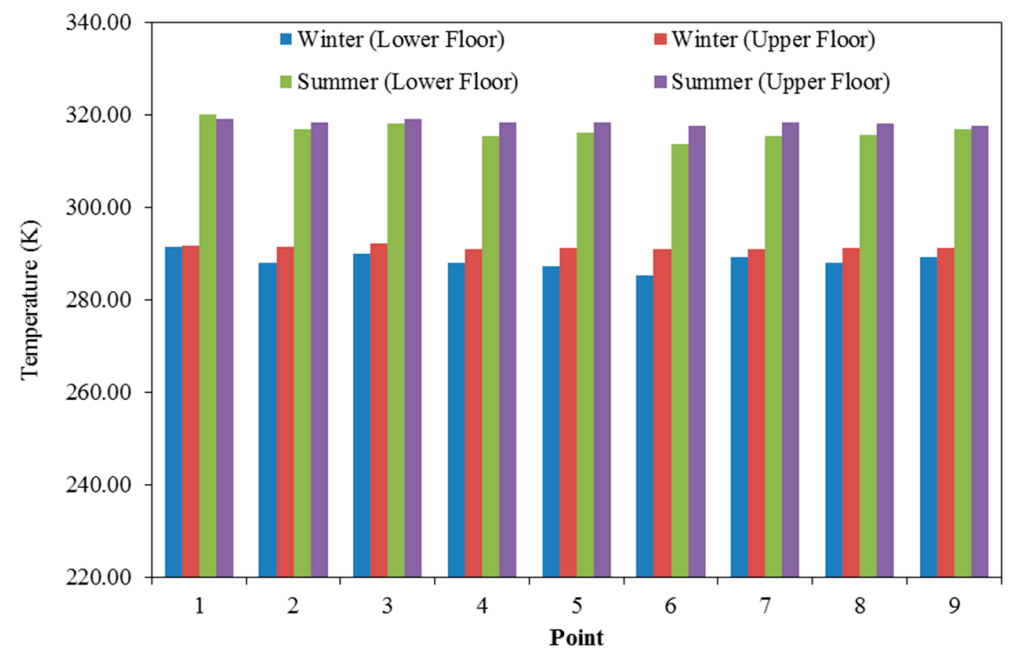

Figure 19. Comparison of the airflow temperature distribution inside the dome house during winter and summer (buoyancy driven flows). 


\section{Conclusions}

In this paper, the potential of natural ventilation (wind induced and buoyancy induced) within a modelled geodesic-type dome under the climatic conditions of Yazd was investigated using Computational Fluid Dynamics (CFD). The standard k-e model was used to define the turbulence kinetic energy and flow dissipation rate within the model. The computational modelling was verified using grid sensitivity analysis and flux balance analysis. The average error between fine and medium mesh results for the velocity was $3.79 \%$. In order to validate the modelling method used in the current study, additional simulation of a similar domed-roof building was conducted for comparison. For the wind-induced flow model, the dome structure was modelled with openings on the roof. For the buoyancy flow model, the geometry was modelled with openings on the roof and also with two windows open in the lower level. The indoor heat gain was simulated by setting a constant heat flux for the floor surfaces. The outdoor wind speed and temperature were based on the local conditions. For a more realistic simulation of the wind flow, the atmospheric boundary layer (ABL) wind profiles for Yazd were used. The results showed that using the upper roof vents as a natural ventilation strategy during winter periods is advantageous and could reduce the indoor temperature and also introduce fresh air. It is suggested that a flow control system is integrated with the roof vents to optimise the indoor velocity and temperature. The results reveal that natural ventilation using a roof vent cannot satisfy thermal requirements during hot summer periods, and mechanical or evaporative cooling is required. To maximise the savings of active cooling and enhance the natural ventilation performance during the cooler months, an adequate amount of thermal mass with a night-cooling strategy would be one potential approach. The airflow inside the building ranges between 0.04 to $0.2 \mathrm{~m} / \mathrm{s}$ with the wind-induced flow, whereas the airflow velocity inside the building ranges from 0 to $0.22 \mathrm{~m} / \mathrm{s}$ with the buoyancy-induced mode. On average, the buoyancy-induced flow was significantly lower compared to the wind-induced flow. However, the analysis showed that the ventilation strategy can still generate air movement inside the building during periods with very low winds. The results also showed that wind-induced flow (from the roof vent) caused better airflow movement and temperature reduction in upper floor, whereas buoyancy-induced flow (roof vent and windows) caused better airflow movement and temperature reduction in the lower floor. In addition, it was found that ventilation rate was not at its highest in the wind-induced case because a considerable quantity of the flow left the top roof vent without entering the building. It is also important to note that other factors which were not investigated in the current study, such as the effects of surrounding buildings, wind directions and solar radiation, should be included in future research. Future modelling work should investigate the impact of different turbulence models on the accuracy of the results. Building Energy Modelling tool could be used to assess the energy performance of the building. The potential for incorporating low-energy cooling technologies such as evaporative cooling and phase change materials (PCMs) should be investigated.

Acknowledgments: The authors would like to acknowledge the support of the University of Sheffield for providing the computational resource for this project.

Author Contributions: The main author (Z.S.) carried out the review and design of the dome house and analysed the data. J.K. carried out the computational modelling. B.H. participated in the analysis of data.

Conflicts of Interest: The authors declare no conflict of interest.

\section{Abbreviations}

The following abbreviations are used in this manuscript:

$\begin{array}{ll}\text { ABL } & \text { Atmospheric Boundary Layer } \\ \text { CFD } & \text { Computational Fluid Dynamics } \\ \text { FVM } & \text { Finite Volume Method } \\ \text { HVAC } & \text { Heating, Ventilation and Air-Conditioning } \\ \text { RANS } & \text { Reynolds-Averaged Navier-Stokes } \\ \text { SIMPLE } & \text { Semi-Implicit Method for Pressure-Linked Equations } \\ \text { TKE } & \text { Turbulence Kinetic Energy }\end{array}$




\section{References}

1. United Nations Environment Programme (UNEP) Sustainable Buildings and Climate Initiative. Available online: http://www.unep.org/sbci/AboutSBCI/Background.asp (accessed on 1 September 2015).

2. Calautit, J.K.; O'Connor, D.; Sofotasiou, P.; Hughes, B.R. CFD Simulation and Optimisation of a Low Energy Ventilation and Cooling System. Computation 2015, 3, 128-149. [CrossRef]

3. Calautit, J.K.S.; Hughes, B.R. Integration and Application of Passive Cooling within a Wind Tower for Hot Climates. HVACER Res. 2014, 20, 722-730.

4. Calautit, J.K.; Chaudhry, H.N.; Hughes, B.R.; Ghani, S.A. Comparison between evaporative cooling and a heat pipe assisted thermal loop for a commercial wind tower in hot and dry climatic conditions. Appl. Energy 2013, 101, 740-755. [CrossRef]

5. Hughes, B.R.; Mak, C.M. A study of wind and buoyancy driven flows through commercial wind towers. Energy Build. 2011, 43, 1784-1791. [CrossRef]

6. Cory, S.; Donn, M.; Pollard, A. Comparison of NZ's energy efficiency regulation and verification assumptions to real building loads and operation. Buildings 2015, 5, 116-129. [CrossRef]

7. Wang, S.; Shen, Z. Impacts of ventilation ratio and vent balance on cooling load and air flow of naturally ventilated attics. Energies 2012, 5, 3218-3232. [CrossRef]

8. Wang, S.; Shen, Z.; Gu, L. The impact of roof pitch and ceiling insulation on cooling load of naturally-ventilated attics. Energies 2012, 5, 2178-2196. [CrossRef]

9. Hughes, B.R.; Calautit, J.K.S.; Ghani, S.A. The development of commercial wind towers for natural ventilation: A review. Appl. Energy 2012, 92, 606-627. [CrossRef]

10. Pixabay. Dome Roof. Available online: https://pixabay.com/en/turkey-istanbul-bosphorus-1405276/ (accessed on 12 August 2016).

11. Passe, U.; Battaglia, F. Designing Spaces for Natural Ventilation: An Architect's Guide; Routledge: Abingdon, UK, 2015.

12. Andrew, J.M. Domes and Solar Radiation. Available online: http://naturalfrequency.com/articles/ solardomes (accessed on 12 December 2015).

13. Wang, S.; Shen, Z. Effects of roof pitch on air flow and heating load of sealed and vented attics for gable-roof residential buildings. Sustainability 2012, 4, 1999-2021. [CrossRef]

14. Calautit, J.K.S.; Hughes, B.R.; Ghani, S.A. A Numerical investigation into the feasibility of integrating green building technologies into row houses in the Middle East. Archit. Sci. Rev. 2013, 56, 279-296. [CrossRef]

15. Hassan, F. Natural Energy and Vernacular Architecture: Principles and Examples with Reference to Hot Arid Climates; The University of Chicago Press: Chicago, IL, USA, 1986.

16. Rika, K.; Asri, D. Improvement proposal for dome houses in Indonesia. In Proceedings of the PLEA 2008-25th Conference on Passive and Low Energy Architecture, Dublin, Ireland, 22-24 October 2008.

17. Pixabay. Dome Building. Available online: https://pixabay.com/en/berlin-reichstag-the-german-volke971799/ (accessed on 16 August 2016).

18. Pixabay. Switzerland Cern. Available online: https://pixabay.com/en/switzerland-sky-clouds-cern-93275/ (accessed on 1 August 2016).

19. Faghih, A.K.; Bahadori, M.N. Experimental investigation of air flow over domed roofs. Iran. J. Sci. Technol. Trans. B Eng. 2009, 33, 207-216.

20. Faghih, A.K.; Bahadori, M.N. Thermal performance evaluation of domed roofs. Energy Build. 2011, 43, 1254-1263. [CrossRef]

21. Atif, A.; Laouadi, A.; Atif, M.R. Predicting optical and thermal characteristics of transparent single-glazed domed skylights. ASHRAE Trans. 1999, 105, 325-333.

22. Khademinejad, T.; Rahimzadeh, S.; Talebizadeh, P.; Rahimzadeh, H.; Sarkardeh, H. CFD modeling of floor heating system in dome shape rooms according to the thermal comfort condition. In Computational Fluid Dynamics Applications in Green Design; CreateSpace: North Charleston, SC, USA, 2014; pp. 277-294.

23. Romero-Gómez, P.; Choi, C.; Lopez-Cruz, I. Enhancement of the greenhouse air ventilation rate under climate conditions of central Mexico. Agrociencia 2010, 44, 1-15.

24. Tlili, O.; Mhiri, H.; Bournot, P. Airflow induced by a room fire: Effect of roof shape and source location. Int. J. Therm. Sci. 2015, 90, 135-149. [CrossRef] 
25. Mahdavinejad, M.J.; Javanroodi, K. Efficient roof shapes through wind flow and indoor temperature, case studies: Flat roofs and domed roofs. Armanshahr Archit. Urban Dev. 2014, 12, 55.

26. Lu, X.; Liu, X.; Lu, S.; Su, Y.; Zhao, Z.; Li, L. Study on air distribution of displacement ventilation in dome cinema in summer. In Proceedings of the 5th International Conference on Advanced Design and Manufacturing Engineering (ICADME 2015), Shenzhen, China, 19-20 September 2015; pp. 1840-1843.

27. Lin, Y.; Zmeureanu, R. Three-dimensional thermal and airflow (3D-TAF) model of a dome covered house in Canada. Renew. Energy 2008, 33, 22-34. [CrossRef]

28. Abohela, I.; Hamza, N.; Dudek, S. Effect of roof shape on energy yield and positioning of roof mounting wind turbines. Renew. Energy 2013, 50, 1106-1118. [CrossRef]

29. Chung, T.J. Computational Fluid Dynamics, 2nd ed.; Cambridge University Press: Cambridge, UK, 2002.

30. Vollaro, A.L.; Galli, G.; Vallati, A. CFD Analysis of convective heat transfer coefficient on external surfaces of buildings. Sustainability 2015, 7, 9088-9099. [CrossRef]

31. Chaudhry, H.N.; Calautit, J.K.; Hughes, B.R.; Sim, L.F. CFD and experimental study on the effect of progressive heating on fluid flow inside a thermal wind tunnel. Computation 2015, 3, 509-527. [CrossRef]

32. Calautit, J.K.S.; Hughes, B.R.; Ghani, S.A. Numerical investigation of the integration of heat transfer devices into wind towers. Chem. Eng. Trans. 2013, 34, 43-48.

33. O'Connor, D.; Calautit, J.K.; Hughes, B.R. A Study of Passive Ventilation Integrated with Heat Recovery. Energy Build. 2014, 82, 799-811. [CrossRef]

34. Valentín, D.; Guardo, A.; Egusquiza, E.; Valero, C.; Alavedra, P. Assessment of the economic and environmental impact of double glazed façade ventilation systems in Mediterranean Climates. Energies 2013, 6,5069-5087. [CrossRef]

35. ANSYS Inc. PDF Documentation for Release 15.0. Available online: http://148.204.81.206/Ansys/readme. html (accessed on 16 August 2016).

36. Mueller, R.K. Geodesic Dome Notes \& Calculator. Available online: https://simplydifferently.org/Geodesic_ Dome_Notes?page=2 (accessed on 12 December 2015).

37. Rahmatmand, A.; Yaghoubi, M.; Rad, E.G.; Tavakol, M.M. 3D experimental and numerical analysis of wind flow around domed-roof buildings with open and closed apertures. Build. Simul. 2014, 7, 305-319. [CrossRef]

38. Richards, P.J.; Hoxey, R.P. Appropriate boundary conditions for computational wind engineering models using the $k-\varepsilon$ turbulence model. J. Wind Eng. Ind. Aerodyn. 1993, 145-153. [CrossRef]

39. Grondzik, W.T.; Kwok, A.G. Mechanical and Electrical Equipment for Buildings, 12th ed.; John Wiley and Sons: Hoboken, NJ, USA, 2014.

40. Autodesk Sustainability Workshop. Equipment and Lighting Loads. Available online: http://sustainabilityworkshop.autodesk.com/buildings/equipment-and-lighting-loads (accessed on 16 August 2016).

41. World Weather Online Average High/Low Temperature for Yazd, Iran. Available online: http://www. worldweatheronline.com/yazd-weather-averages/yazd/ir.aspx (accessed on 12 December 2015).

42. Ali, M. Feasibility study of harnessing wind energy for turbine installation in province of Yazd in Iran. Renew. Sustain. Energy Rev. 2010, 14, 93-111.

(C) 2016 by the authors; licensee MDPI, Basel, Switzerland. This article is an open access article distributed under the terms and conditions of the Creative Commons Attribution (CC-BY) license (http://creativecommons.org/licenses/by/4.0/). 